\title{
Stoic Sequent Logic and Proof Theory
}

\author{
SUSANNE BOBZIEN \\ All Souls College, University of Oxford
}

\begin{abstract}
This paper contends that Stoic logic (i.e. Stoic analysis) deserves more attention from contemporary logicians. It sets out how, compared with contemporary propositional calculi, Stoic analysis is closest to methods of backward proof search for Gentzen-inspired substructural sequent logics, as they have been developed in logic programming and structural proof theory, and produces its proof search calculus in tree form. It shows how multiple similarities to Gentzen sequent systems combine with intriguing dissimilarities that may enrich contemporary discussion. Much of Stoic logic appears surprisingly modern: a recursively formulated syntax with some truth-functional propositional operators; analogues to cut rules, axiom schemata and Gentzen's negation-introduction rules; an implicit variablesharing principle and deliberate rejection of Thinning and avoidance of paradoxes of implication. These latter features mark the system out as a relevance logic, where the absence of duals for its left and right introduction rules puts it in the vicinity of McCall's connexive logic. Methodologically, the choice of meticulously formulated meta-logical rules in lieu of axiom and inference schemata absorbs some structural rules and results in an economical, precise and elegant system that values decidability over completeness.
\end{abstract}




\section{Introduction}

Stoic logic is no less ingenious than Aristotle's syllogistic. Still, there is a marked tendency amid contemporary logicians to ignore it, despite the fact that several detailed reconstructions have been published since the 1950s. ${ }^{1}$ This paper hopes to increase interest in Stoic logic among proof theorists and more generally among those who place the beginning of propositional logic with Boole, Frege and Russell and the beginning of proof theory with Gentzen. The Stoics were in effect the first to develop a propositional logic, and the way in which they did so anticipated proof theory. The depth of their understanding of logic and the sophistication with which they tackled many questions of contemporary relevance is astounding.

The present paper uses current formal methods and terminology in a historically faithful representation and formalization of the Stoic system, and relates this system to contemporary approaches to deduction. The paper lingers neither on historical detail nor on textual difficulties. For these, readers are referred to Bobzien $1996 .{ }^{2}$ Suffice it to note that Stoic logic survives in a fragmentary state, but with just enough information to reconstruct the Stoic method of analysis with some certainty, and that with the addition of a couple of plausible assumptions a full calculus results that is historically credible and that manifests a logical

\footnotetext{
${ }^{1}$ Discussions and reconstructions of the Stoic system of deduction are provided e.g. by Lukasiewicz 1934, Mates 1962, Becker 1957, Kneale and Kneale 1962, Corcoran 1974, Frede 1974, Gould 1974, Mueller 1979, Egli 1983, Ierodiakonou 1990, Mignucci 1993, Milne 1995, Bobzien 1996, Bobzien 1999, Hitchcock 2006, Milne 2012. The Stoic system of deduction is all but ignored in the Handbook of the History of Logic, Vol.1, Greek, Indian and Arabic logic (Gabbay and Woods 2004). Generally, the number of papers on Stoic logic in journals that publish contemporary and historical papers is minuscule compared to that on Aristotelian logic.

${ }^{2}$ The paper aims to keep to the original Stoic theory of deduction as much as is possible, both in content and form, so as not to obscure any features that may turn out to be of logical interest. In this respect the approach differs from Becker 1957, Mueller 1979, Mignucci 1993, Milne 1995 and Milne 2012. Since Chrysippus, third head of the Stoa, was the most highly regarded and most productive Stoic logician by a large margin, Chrysippus' view is considered authoritative wherever there is a difference in Stoic positions on logically pertinent issues. All translations are my own.
} 
achievement in propositional logic that can hold its own against those from the late19th to the early $21^{\text {st }}$ centuries.

In particular, Stoic logic emerges as a substructural propositional sequent logic tailored to proof search. There are several significant similarities to Gentzen 1933 and 1934, and to more recent backward Gentzen-style proof-search systems as used in structural proof theory, logic programming and automated theorem proving. ${ }^{3}$ Unlike Gentzen systems, Stoic sequent logic generates most of the logical structure with the axiom schemata and the focus appears to be on decidability rather than completeness. The logic has a subformula property and is decidable, both resulting from the Stoic choice of axioms. The Stoics deliberately opted for a relevance-logical consequence relation in order to evade the paradoxes of material and strict implication. A variable sharing principle and the absence of Thinning confirm that Stoic logic is a relevance logic. Meticulous definitions of all basic logical components that provide analogues to schemata for propositions, sequents and inference rules together with accounts of propositions that allow for recursive structure, matched by a (partially non-classical) truthconditional semantics, lay the basis for a highly principled and elegant system whose disparities from contemporary standard propositional logics should pique the interest of logicians who like to explore alternatives to the standards of classical logic, both in substance and in presentation.

The reference of automated theorem proving and logic programming in a paper on the history of logic may surprise. The reason for such reference is that certain questions that have been considered of secondary importance by logicians of the $20^{\text {th }}$ century are of importance both to

\footnotetext{
${ }^{3}$ Troelstra and Schwichtenberg 1996 offer a general overview of how proof search can be done in sequent calculi. For a useful introduction to automated theorem proving see Fitting 1996. Two examples of automated proof search based on sequent calculi are Graham-Lengrand 2013 and Muñoz Toriz et al 2014.
} 
those without a formal apparatus and modern reading and writing equipment (books, pen and paper) and to logic programming - if not in quite the same way. Where $20^{\text {th }}$ century logicians are interested primarily in what can be proved in logical systems, Stoic logicians and logic programmers alike have to face the question of how we prove with logical systems, on at least two counts. First, in either case it is a question of resources such as memory and computation space and time. Thus it becomes relevant how long it takes to prove and how complex the proofs are. Reading and writing on papyrus scrolls or very small clay tablets restricts one enormously (try it), and in antiquity logic was done in spoken language (and presumably in thought) rather than on 'paper' much more extensively than nowadays. Thus there was a premium on small numbers of easily memorisable rules and definitions, without loss of precision and rigour. Language regimentation and a well-defined logical vocabulary provided some of the latter. As we will see, the choice of meta-linguistic rules in lieu of object-language schemata assisted with the former. Second and related, both logic programming and Stoic logic are concerned with input-output models of testing validity. In the Stoic case, having a technique for establishing that certain statements are incontestable independent of their meaning considerably raises the standards in dialectical discourse and in the defence of philosophical tenets. As a result of this focus, decidability and efficiency are more central concerns than completeness.

The paper is structured as follows. $§ 1$ presents Stoic syntax for propositions and sequents plus their distinction between object and meta-language. $\$ 2$ introduces the general method of analysis. $\S 3$ adds the inference rules, $\$ 4$ the meta-logical axiom schemata. $§ 5$ provides examples of Stoic proof search and a comparison with contemporary systems, which jointly lead to a formalization of Stoic analysis in terms of a proof-tree calculus. $\$ 6$ considers the directionality of Stoic proof search. $\S 7$ focuses on structural rules in Stoic logic, explains in 
what way the logic is substructural and contains a variable sharing principle. $\S 8$ briefly examines questions of normal form, subformula property, decidability and efficiency. An appendix offers a proof of the subformula property.

\section{Syntax: Formulae (Propositions) and Sequents (Arguments)}

Stoic logic contains both metalinguistic expressions and object-language logical constants and schematic letters. A Stoic argument is a collection of propositions (D.L.7.45). Stoic propositions (axiômata) are not linguistic items but the semantic correlates to assertible sentences which, once appropriately regimented, are supposed to be isomorphic with the propositions which they signify. Stoic propositions A, B, C, ... are either atomic or nonatomic. A Stoic stock example for an atomic proposition is 'It is day'. Non-atomic propositions are built from atomic ones by means of propositional connectives. There are four kinds of non-atomic propositions: negations, conjunctions, exclusive disjunctions and conditionals. The component propositions in the largest scope of a conjunction are conjuncts, of a disjunction disjuncts, and of a conditional antecedent and consequent. The logical connectives are, in order, 'it is not the case that ...', 'both ... and ---', either ... or ---' and 'if ..., ---', for which I use the symbols ' $\neg$ ', '^’, ' $\oplus$ ', ' $\rightarrow$ ' respectively. The Stoics regiment the placement of their connectives in order to remove structural ambiguities. The resulting functional analogue to a bracketing device is punctuation free and similar to Polish notation: 'both either A or B and C' is syntactically distinguished from 'either A or both B and C'. To make things accessible, I follow modern conventions with respect to disambiguation of formulae through bracketing. ${ }^{4}$ Stoic logic is syntactically closed under its four connectives,

\footnotetext{
4 The English-language equivalent of the Stoic punctuation-free formulation of e.g. $((\mathrm{A} \rightarrow \mathrm{B}) \wedge(\neg \mathrm{A} \rightarrow \mathrm{B})) \wedge(\mathrm{A} \oplus \mathrm{B})) \rightarrow \mathrm{B}$ would be 'If both both if $\mathrm{A} \mathrm{B}$ and if not $\mathrm{A}$ B and either A or B B'. (Bobzien 1996 uses this notation.) Read or said with the right intonation and pauses, this is clear enough: intonation and pauses provide an invisible supporting punctuation. Polish style symbolism is used by Egli 1983 and Hitchcock 2006, and seems workable, too. Yet it distracts somewhat from the
} 
and propositions can be of arbitrary complexity, with finite length and depth here assumed. Instead of the predominant contemporary distinction between atomic and non-atomic propositions, the Stoics present their logic as based on the distinction between simple and non-simple propositions. Simple propositions are basically (positive and negative) literals. Non-simple propositions are non-literals. They are negative if negation has largest scope, otherwise positive.

Additionally, Stoic analysis makes use of the meta-linguistic notion of contradictories (or complements, antikeimena). Contradictories are defined as any pair of propositions in which one proposition exceeds the other by a negation (S.E.M.8.89, cf. D.L.7.73). ${ }^{5}$ This has the odd consequence that positive propositions have one contradictory while negative ones have two. Since the Stoics maintained that the double negation of A, $\neg \neg$ A, posits A (D.L.7.69), I mostly disregard this idiosyncrasy. Of the four kinds of non-atomic propositions, negation and conjunction are truth-functional. Disjunction and conditional are not: their truthconditions include a modal element, not unlike disjunction and conditional in some substructural logics (see §7).

A formal syntax for the Stoic language of propositions and sequents (' $\mathrm{L}_{S}$ ') includes the atomic letters $\mathrm{p}, \mathrm{q}, \mathrm{r} \ldots$ for atomic propositions. In examples, e.g. of proof search, p, q, r ...

similarities and differences between Stoic and contemporary deduction that are the main topic of this paper.

${ }^{5}$ There is no extant evidence that the Stoics explicitly discussed multiply negated propositions. The definition of negation (which has to be and can be pieced together from several sources) that a negation is a proposition that is governed by a negator (oukhi) certainly allows for such cases. Since the Stoics considered negations that had the negator (oukhi) govern non-simple propositions as well as doubly negated propositions, we can assume that they were aware of the possibility of, and would have allowed, multiply negated propositions. If these ever occurred in examples, they would almost certainly have been mutilated by scribes. (Copying was required roughly every fifty years until codices became common.) Stoic analysis does not require their existence. 
are always distinct. Then, if $\mathrm{A}$ and $\mathrm{B}$ are propositions of $\mathrm{L}_{\mathrm{S}}$, so are $\neg \mathrm{A}$ and $(\mathrm{A} \rightarrow \mathrm{B})$ and $(\mathrm{A} \wedge \mathrm{B})$ and $(\mathrm{A} \oplus \mathrm{B})$. Nothing else is a proposition of $\mathrm{L}_{\mathrm{S}} \cdot{ }^{6}$ In addition, I use the postfixed metalinguistic contradictoriness operator '*' ('is the contradictory of') for Stoic contradiction. It occurs in the presentation of inference rules and axiom schemata, but never in proofs themselves. With the above proviso on Stoic negation, $A^{*}$ is defined in terms of negation as follows: $(\neg \mathrm{A})^{*}=\mathrm{A}$ for negative $\mathrm{A}$, and for positive $\mathrm{A}, \mathrm{A}^{*}=\neg \mathrm{A}$. The contradictory of a contradictory is then itself: $\mathrm{A}^{* *}=\mathrm{A}$. (Without the proviso, for any contradictory of $\mathrm{A}$ there is one contradictory that is A. In some cases there are two contradictories, one of them being A. This is sufficient for the logic's decidability, but cumbersome for proofs, and is henceforth ignored.)

The Stoics themselves clearly distinguished between object-language and meta-linguistic expressions. For example, they insist that in a formally valid argument a conditional as assumption must be expressed as 'if A, B'. Replacing 'if A, B' by ' $<$ the proposition> A follows from <the proposition> B' removes the argument's formal validity, despite the fact that both sentences have the same meaning or logical power (isodunamein), and similarly with 'it is not the case that A' and 'the <proposition> A is false' (cf. Alex. An.Pr.373, 28-35; D.L.7.78).

For convenience, I introduce the notions of a subformula and a \pm subformula. A is a subformula of itself and of $\neg \mathrm{A}$; if any of $(\mathrm{B} \rightarrow \mathrm{C}),(\mathrm{B} \oplus \mathrm{C})$, or $(\mathrm{B} \wedge \mathrm{C})$ is a subformula of $\mathrm{A}$,

\footnotetext{
${ }^{6}$ In fact, the Stoics seem to have recognized the special case of a multi-disjunct exclusive disjunction (S.E.P.H.1.69) for which see below $\$ 4$ and e.g. Jennings 1994, ch.10. Their forms can be expressed as $\mathrm{A} \oplus \mathrm{B} \oplus \mathrm{C}, \mathrm{A} \oplus \mathrm{B} \oplus \mathrm{C} \oplus \mathrm{D}$, etc. It is a matter of debate whether they also recognized conjunctions with more than two conjuncts, see Bobzien 2011, esp. 172-4 and 182-6, and I am sceptical. In any event, this paper considers only two-conjunct cases, since these are the only ones explicitly mentioned in the context of analysis; inferentially multi-conjunct cases could be covered by nested two-conjunct conjunctions.
} 
then so are $\mathrm{B}$ and $\mathrm{C}$; if $\neg \mathrm{B}$ is a subformula of $\mathrm{A}$, then so is $\mathrm{B}$. I stipulate that if $\mathrm{B}$ is a \pm subformula of $\mathrm{A}$, then so is $\neg \mathrm{B}$ and that every subformula of $\mathrm{A}$ is a \pm subformula of $\mathrm{A}$.

The arguments (logoi) to which the Stoic method of proof search is applied are composed of atomic and non-atomic propositions of the kind described. They consist of a finite number of assumptions and a conclusion (D.L.7.45). The assumptions are not ordered (see also $\S 3,4 \&$ 7). The conclusion is introduced by a logical constant 'therefore' or 'hence'. ${ }^{7}$ In the contemporary sequent-logical terminology that I will use, Stoic arguments are antecedentsuccedent sequents with the following syntactic constraint: They have at least two (and that is two distinct) propositions as assumptions in the antecedent and precisely one as succedent. ${ }^{8}$ Such Stoic sequents will be represented as $\Gamma \vdash \mathrm{A}$, with $\Gamma$ for the antecedent and A for its succedent. The syntactic turnstile ' $\vdash$ ' stands for the Stoic logical constant 'therefore' and indicates the consequence relation for Stoic sequents; just as in modern logic it indicates that in the sequent the succedent follows from the antecedent propositions in accordance with the given rules. With the Stoic syntactic constraints, such sequents are singleton-succedent sequents where the cardinality of the antecedent $\Gamma$ is at least two. Thus $\mathrm{p} \vdash \mathrm{r}$ and $\mathrm{p} \vdash \mathrm{p}$ and $\mathrm{p} \wedge \mathrm{q} \vdash \mathrm{p}$ are not Stoic sequents.

A complication is introduced by the fact that Stoic logic has propositions, not sentences, as its objects. Whether something is an argument (or Stoic sequent) is determined by whether it has

\footnotetext{
7 To bring out the form of an arguments and structure of a proof (analysis), the Stoics used abbreviatory devices termed modes (tropoi), in which atomic propositions were replaced by Greek ordinals (D.L.7.79, S.E.M.8.235-8). It is an open question whether the modes replaced only atoms or also non-atomic propositions with numerals. Likewise, it is unclear whether the modes had more than a simple abbreviatory function. I bypass both questions. The use of 'mode' in contemporary modal logic differs from the Stoic notion of a mode, which has nothing to do with modalities.

${ }^{8}$ These syntactic constraints were taken for granted by all Stoics except Antipater, who allowed for certain very specific one-assumption arguments (S.E.P.H.2.167, S.E.M.8.443).
} 
at least two (and that is two distinct) propositions as assumptions. In an argument a proposition can only be assumed once. The Stoics were aware that in our dealings with logic we use natural language to express propositions; further that natural language is ambiguous and that its structure may not mirror that of the proposition to be expressed. They instituted a form of language regimentation that aims at a bijective relation between propositions and their linguistic expressions - at least in the context of logic and philosophical argumentation (e.g. Bobzien 1999, pp.103-4). For Stoic sequents, the regimentation appears to have been a notational principle or notational convention that in the antecedent any proposition be recorded only once: It is not occurrences of propositions, but propositions that are represented (or there is a restriction to one occurrence of each proposition in the antecedent). It follows that e.g. $p, p \vdash p \wedge p$ and $p, p, q \vdash r$ are not Stoic sequents. A fortiori, $p, q \vdash p$ and $p, p, q \vdash p$ are not the same Stoic sequent. Generalizing, we can say that in Stoic logic any expression of the form $\Gamma, A, A \vdash B$ (in Stoic terms 'the conclusion $B$ follows from the assumptions $\Gamma, A$, and $\mathrm{A}$ ' or ' $\Gamma, \mathrm{A}$, and A deduce B') is ill-formed. ${ }^{9}$

The notational constraint to one occurrence per proposition in the antecedents has consequences for how they should be understood. The Stoics themselves never say what kind of mathematical entities their antecedents are. Rather, it is by the consistent way in which they formulate their rules and schemata and generally construct their logic that we make assumptions about what contemporary mathematical objects are most fitting to represent the

\footnotetext{
${ }^{9}$ Why would the Stoics regard such sequents as ill-formed? First, this is likely to have its ground in the Stoic individuation criteria for assumptions (Bobzien 1996, 176-179). Second, the dialectical origins of Stoic logic may be relevant: If assumptions have to be agreed upon, then once an assumption is agreed upon, it cannot be agreed upon again for the same argument, if agreeing was understood as being performative (just as you can't marry a person again when you just married them). Third, if the above four cases were provable Stoic sequents, then one-assumption arguments could be made into two-assumption arguments simply by repeating an assumption. We can be confident that such a loophole would have escaped neither the Stoics nor their ancient critics.
} 
Stoic antecedents. It is an unsettled question whether these are sets, multisets or some less specified collection of propositions. ${ }^{10}$ Since the order of antecedent propositions is logically irrelevant and the multiplicity of an antecedent proposition is logically relevant, multisets seem an apt choice. Since antecedent propositions in a Stoic sequent do not permit repetition, I suggest that we understand Stoic antecedents as multisets in multiset notation with a syntactic restriction to single (or unary) multisets; that is, to multisets in which the multiplicity of every element of the multiset is 1 . Thus, although any single multiset corresponds to an ordinary set, the multiset notation prevents for example the representation of $\{\mathrm{A}, \mathrm{B}\}$ as $\{\mathrm{A}, \mathrm{A}, \mathrm{B}\}$, since in the latter case $\mathrm{A}$ has multiplicity 2 and is no longer a single multiset. Upper-case Greek letters $\Gamma, \Gamma^{\prime}, \Gamma^{\prime \prime}, \boldsymbol{E}, \ldots$ then stand for single multisets; the comma in $\mathrm{A}, \mathrm{B}$ separates two members of the multiset, the comma in $\Gamma$, A stands for the single multiset $\Gamma \cup \mathrm{A}$, that is, the union multiset (or lowest common multiple) of $\Gamma$ and $\{\mathrm{A}\}$, etc.; and $\Gamma, \Gamma^{\prime}$ stands for the single multiset $\Gamma \cup \Gamma^{\prime}$, that is, the union multiset of $\Gamma$ and $\Gamma^{\prime}$, etc. Throughout the paper, reasons will be collected that support the suggestion that Stoic antecedents can be understood as multisets in this way.

\section{Stoic Analysis as a Method of Proof Search}

The Stoics call arguments that are valid on account of their form syllogisms - hence the name 'Stoic syllogistic' for their system of deduction. ${ }^{11}$ The Stoic criterion for syllogismhood is syntactic. A syllogism is a valid argument precisely if it either is a so-called indemonstrable argument (short, indemonstrable) or is an argument that is reducible by certain inference

\footnotetext{
${ }^{10}$ Milne 1995, 41 suggests sets, Hitchcock 2006, \$2.2 rejects sets, Bobzien 1996 uses the sequential notation $\mathrm{A}_{1}, \mathrm{~A}_{2}, \mathrm{~A}_{3}$ and avoids the issue.

${ }^{11}$ Other kinds of arguments that the Stoics considered valid are disregarded in this paper.
} 
rules (themata) to such indemonstrables (D.L.7.78). ${ }^{12}$ Such reduction was called analysis (e.g. S.E.M.8.229) ${ }^{13}$, hence 'Stoic analysis'.

Stoic usage of the terms 'analysis' and 'to analyse' shows that they employ analysis in at least two ways. First, 'analysis' is a generic term for a method. A key element of this general method is captured if one calls it a proof-search method for sequents. Here proof search is a procedure that is applied to sequents and which searches for a proof (or derivation) of an end sequent, thereby - if successful - constructing a proof of it. Second, 'analysis' is used for individual instances of the successful application of that method. Where 'analysis' is used for such an instance, we have a successful proof search. Such an instance is a process: a proof search that generates a proof.

\section{Inference Rules (Themata)}

Stoic logic has four inference rules, called themata. ${ }^{14}$ These themata are sequent-logical inference rules: they derive sequents from sequents. Two are extant. The other two need

12 'Syllogisms, i.e. syllogistic arguments, are deductively valid arguments which either are indemonstrable (anapodeiktoi) <arguments> or are reducible to indemonstrable <arguments> in accordance with one or more of the themata.' (D.L.7.78). The Greek anapodeiktos and Latin indemonstrabilis both permit translations as 'indemonstrable' and as 'undemonstrated' (e.g. Frede 1974, pp. 127-131). My preference is the generally used 'indemonstrable' with regards to Stoic logic. Stoic terminology is rarely arbitrary. In Stoic logic, the cognate apodeixis ('demonstration') is an epistemic term. A demonstration is an argument (logos) that concludes from what is more easily grasped that which is less easily grasped (DL.7.45). It is plausible that the Stoic term anapodeiktos was related to the Stoic term apodeixis as follows. Anapodeiktoi arguments are those 'which do[es] not need an apodeixis' (S.E.M.2.223), because there is nothing that is more easily grasped than they: It is 'evident from themselves that they are valid' (S.E.M.ibid.). 'Being evident', like 'being grasped, is an epistemic term. From the indemonstrability of the anapodeiktoi it does not follow that they cannot have an analysis; only that such an analysis does not make their validity more easily grasped.

13 'Non-simple <syllogisms> are those that are composed from simple ones and that need an analysis into these $<$ simple ones $>$ in order for us to be able to know that they, too, are valid' (S.E.M.8.228-9). For this passage see also $\S 4$.

${ }^{14}$ Passages that explicitly mention the themata are D.L.7.78, Galen Plac.Hipp.Plat.2.3.18-19, Apuleius De interpretatione 191.6-10, Alexander An.Pr. 284.10-17, 278.8-14, 164.27-31, Simplicius In Arist.Cael. 236.33-237.4, [Ammon] An.Pr. 68.13-14 (clearly misunderstanding the Stoics); cf. also 
reconstruction with the help of a dozen or so relevant surviving passages. The themata were expressed in natural-language conditionals starting with 'when' (rather than 'if') and were carefully worded. In these conditionals (given below), the conditional clause refers to the premise-sequent(s) or premise(s), and the main clause refers to the concluding sequent or conclusion. ${ }^{15}$ It appears that the inference rules came each (i) in a basic form, in which the premises have two antecedent propositions, and (ii) in an extended form, in which the number of antecedent propositions is two or more in one of the premises. By using the themata to analyse complex sequents into simpler ones, one can ascertain whether the complex sequent has a proof (or derivation), or in Stoic terms, is a syllogism, S.E.M.8.229. ${ }^{16}$

Qua inference rule, the first thema is a sequent-logical rule of contraposition:

First Thema: When from two <propositions> a third is deduced, then from either of them together with the/a contradictory of the conclusion the/a contradictory of the other is deduced. (Apul.Int.191.6-10)

Its extended version is:

Galen Inst.Log.6.5. These passages are provided in the original Greek or Latin with English translation in Bobzien 1996.

${ }^{15}$ There are no Stoics terms for the sequent-logical premises and conclusion. In cut rules, later Stoics may have referred to the relation between the two premises by saying that the second premise is added on (epiballomenon) the first premise, e.g. Alex.An.Pr.274, 283, 284, but this may be Peripatetic rather than Stoic terminology.

${ }^{16}$ The Stoics distinguished simple and non-simple sequents (see $\$ 4$, esp. fn 25) and maintained that the non-simple ones were composed from and analysed into the simple ones. Based on this distinction, I assume that when a cut rule is used in a successful analysis, the Stoics considered the premises to be simpler than the conclusion. (So also Corcoran 1974, 180-1.) This is in line with the system satisfying the subformula property ( $\$ 8$ and Appendix). 
When from two or more <propositions> another is deduced, then from all but one of them together with the/a contradictory of the conclusion the/a contradictory of the remaining one is deduced. (Based on Galen Inst.Log.VI.5)

Formally, the first thema is, with $\Gamma$ for context, $A$ for principal formula, a horizontal line or inference stroke for the meta-linguistically used 'when/then' (besides ' $\vdash$ ' for 'follows', '*' for contradictory as introduced above)

$$
\frac{\Gamma, \mathrm{A} \vdash \mathrm{B}}{\Gamma, \mathrm{B}^{*} \vdash \mathrm{A}^{*}}
$$

$\Gamma$ has cardinality one in the basic version and $\Gamma \neq \varnothing$ in the extended version. The Stoic metalinguistic formulation in terms of pairs of contradictories (as opposed to 'negation') leaves it unspecified which of the relevant propositions surpasses the other by a negator (and has greater depth). Given the above proviso about negations, the metalinguistic $\mathrm{A}^{*}$ and $\mathrm{B}^{*}$ could be replaced with the object language $\neg \mathrm{A}$ and $\neg \mathrm{B}$ without a change to the logic. For the Stoics, though, $\mathrm{A}^{*}$ and $\mathrm{B}^{*}$ could be affirmative. $\mathrm{T} 1$ is invertible as it stands. (We will see below that axioms can only be placed in the top line.)

We get a glimpse of the sequent-logical function of T1, if we look for the closest analogue in Gentzen and for what may appear to be missing in the Stoic system. The system has axiomatic rules for conditional, conjunction and disjunction and cut rules. It has no rule for negation. Now consider Gentzen's negation introduction rules $\mathrm{L} \neg$ and $\mathrm{R} \neg$ (Gentzen 1934) for LK:

$$
(\mathrm{L} \neg) \quad \frac{\Gamma \vdash \Delta, \mathrm{A}}{\neg \mathrm{A}, \Gamma \vdash \Delta}
$$




$$
(\mathrm{R} \neg) \quad \frac{\mathrm{A}, \Gamma \vdash \Delta}{\Gamma \vdash \Delta, \neg \mathrm{A}}
$$

$\mathrm{L} \neg$ and $\mathrm{R} \neg$ cannot be expressed in Stoic logic, since Stoic sequents have precisely one succedent proposition. If one tried to move a succedent formula with changed polarity into the antecedent, the succedent would be empty. If one tried to move an antecedent formula with changed polarity into the succedent, then the succedent would contain two propositions. One can avoid either case by simultaneously moving a proposition in the other direction, with changed polarity. This results in one of the four object-language rules that are jointly captured by the Stoic meta-linguistic T1. Thus the first thema can be considered the Stoic rule for negation, and $\mathrm{T} 1$ as its representation in the form of an inference schema.

The third thema belongs to the family of cut rules. (Expressions in brackets provide the extended version.)

Third Thema: When from two propositions a third is deduced, and from the third and one (or more) external proposition(s) another is deduced, then this other is deduced from the first two and the external(s).

'a/the third' refers to the cut formula. What is uncommon for a cut rule is the expression 'external propositions'. I assume that such propositions are external to (or distinct from) the antecedent propositions of the first premise. Alternatively, they could be external to both antecedent and succedent of that sequent.

The thema can be represented as an inference schema, with the bold $\mathbf{E}$ (epsilon) denoting the multiset of external propositions $\left(\Gamma, \Gamma^{\prime}, \ldots\right.$ being reserved for all other multisets, to preserve 
the distinction between external and non-external propositions), ' $\vdash$ ' for 'follows' and the horizontal line for the meta-linguistically used 'when/then':

$$
\underline{A, B} \vdash \mathrm{C} \quad \mathrm{C}, \mathbf{E} \vdash \mathrm{D}
$$

$$
\mathrm{A}, \mathrm{B}, \mathbf{E} \vdash \mathrm{D}
$$

$\mathbf{E}$ has cardinality one in the basic version; $\mathbf{E} \neq \varnothing$ in the extended version.

Rules of contraposition and cut rules appear to have been the only inference rules for propositional sequents in antiquity. This alone makes it probable that the remaining two Stoic themata are cut rules as well. The use of 'external proposition' in the third thema, too, indicates that there was more than one cut rule in Stoic analysis (see also $§ 7$ and Ierodiakonou 1990, pp.72-74.). The reconstruction in Bobzien 1996, which I follow unless noted otherwise, is based in addition to these two points on all indirect evidence for Stoic themata, for ancient cut rules, and what we know overall of ancient logic. ${ }^{17}$ In their most straightforward reconstruction, the second and fourth themata and their schematic representation then are:

Second Thema (reconstructed): When from two propositions a third is deduced, and from the third and one - or both - of the two another is deduced, then this other is deduced from the first two.

$$
\underline{\mathrm{A}, \mathrm{B} \vdash \mathrm{C} \quad \mathrm{C}, \mathrm{A}(\mathrm{B}) \vdash \mathrm{D}}
$$

$$
\mathrm{A}, \mathrm{B} \vdash \mathrm{D}
$$

\footnotetext{
${ }^{17}$ Bobzien 1996, pp.152-180. Hitchcock 2006 adopts Bobzien's reconstruction.
} 
Fourth Thema (reconstructed): When from two propositions a third is deduced, and from the third and one - or both - of the two and one (or more) external proposition(s) another is deduced, then this other is deduced from the first two and the external(s).

$$
\underline{A, B} \vdash \mathrm{C} \quad \mathrm{C}, \mathrm{A}(\mathrm{B}) \mathbf{E} \vdash \mathrm{D}
$$

$$
\mathrm{A}, \mathrm{B}, \mathbf{E} \vdash \mathrm{D}
$$

$\mathbf{E}$ has cardinality one in the basic version; $\mathbf{E} \neq \varnothing$ in the extended version. T2 and $\mathrm{T} 4$ are metalinguistic rules. Each covers two object-language rules, one that includes, one that excludes, $\mathrm{B}$ in the second premise.

All three cut schemata T2-T4 have in their first premise a two-proposition antecedent, for example an axiom, and $\mathrm{C}$ as cut formula. They differ with regard to the remaining antecedent propositions of the second premise: in T3 they are not in the antecedent of the first premise; in the T2 they are; in T4 some are, some aren't. From the perspective of classical or intuitionistic logic, this distinction may appear unmotivated. From a Stoic perspective, it is required to avoid multiplicities of any antecedent proposition. Generally, from an ancient viewpoint it mattered. ${ }^{18}$ From a relevance-logical viewpoint, it matters, too ( $\$ 7$ below).

There are alternative reconstructions that cover the same logical ground, an obvious one being

\footnotetext{
${ }^{18}$ E.g. Alex.An.Pr.164.27-31 with 10.5-11.4 and 19-20; Gal.Plac.Hipp.Plat.2.3.18ff.
} 
Second Thema' (reconstructed): When from two propositions a third is deduced, and from the third and one of the two and zero or more external propositions another is deduced, then this other is deduced from the first two and the external(s).

$$
\underline{\mathrm{A}, \mathrm{B} \vdash \mathrm{C} \quad \mathrm{C}, \mathrm{A}, \mathrm{E} \vdash \mathrm{D}}
$$

$$
\mathrm{A}, \mathrm{B}, \mathbf{E} \vdash \mathrm{D}
$$

Fourth Thema'(reconstructed): When from two propositions a third is deduced, and from the third and the two and zero or more external propositions another is deduced, then this other is deduced from the first two and the external(s).

$$
\underline{\mathrm{A}, \mathrm{B} \vdash \mathrm{C} \quad \mathrm{C}, \mathrm{A}, \mathrm{B}, \mathbf{E} \vdash \mathrm{D}}
$$

\section{$\mathrm{A}, \mathrm{B}, \mathbf{E} \vdash \mathrm{D}$}

The natural ordering would then be $\mathrm{T} 3, \mathrm{~T} 2^{\prime}, \mathrm{T} 44^{\prime}$. From a contemporary perspective, the choice of $\mathrm{T}^{\prime}$ and $\mathrm{T} 4$ ' may be neater. However, it does not tally well with the multiply recorded Peripatetic objection that the second thema was useless, as illustrated with possible applications of $T 2.2^{\prime}$ has applications that are not useless from a Peripatetic perspective, namely those in which $\mathbf{E} \neq \varnothing .{ }^{19}$

The natural-language wording of the themata leaves the order of the antecedent propositions in premise(s) and conclusion undetermined (which accords with the proposed reading of Stoic antecedents as multisets). Moreover, it ensures that the premise(s) and conclusions can

\footnotetext{
${ }^{19}$ Apparently, there were experts trained in analysis with the first and second themata and other experts trained in analysis with the third and fourth themata (Gal.Plac.Hipp.Plat. 2.3.18, see also Bobzien 1996, 143). In the alternative reconstructions $\mathrm{T} 2$ 'and $\mathrm{T} 4$ ' would pair up more naturally than $\mathrm{T} 3$ and T4'. Formulations with 'zero or more' (or 'none or more') are also unusual for antiquity.
} 
have non-atomic propositions of arbitrary complexity in antecedent and succedent; and, with some syntactic restriction, it makes the themata cover the terrain of a substitution rule (as is set out in §7) or of inference schemata, as used here. These points are all preserved in the formal representation.

Application of the themata: In principle, the themata can be used in proof searches in two directions: forwards, from premise(s) to conclusion, in a process of proof construction that starts with one or more axiomatic sequents and concludes with a non-axiomatic one; and backwards, from the conclusion to the premise(s), in a process of proof construction of a nonaxiomatic sequent by reducing it to one or more axiomatic sequents. If you picture Stoic deductions as trees, you can think of 'forward' as 'leaves-first' and 'backward' as 'root-first'. (The expressions 'forward' and 'backward' are taken from contemporary proof theory and do not reflect Stoic perspective.)

De facto, in Stoic analysis (and this is the only Stoic deductive method we know of!) the inference rules are used backwards. Stoic proof search works from complex sequents to simpler ones and from non-axiomatic sequents to axiomatic ones. The backward use of the themata notwithstanding, their natural language formulations are 'forward', just as is standard for the inference schemata in contemporary backward methods. For that reason, and for ease of reading, I represent the application of the themata in the familiar direction with leaves at the top and the root at the bottom (even if this may be un-Stoic). The name of the thema used is added level with the inference line, for instance

$\mathrm{p}, \mathrm{p} \rightarrow \neg \mathrm{q} \vdash \neg \mathrm{q}$ $\mathrm{T} 1$

$\mathrm{p}, \mathrm{q} \vdash \neg(\mathrm{p} \rightarrow \neg \mathrm{q})$ 
('*) cannot be used in a proof itself, because it is a meta-linguistic operator.) In the formalized Stoic system, each thema then sanctions the move from the sequent below the horizontal line to the sequent(s) above that line, on the assumption that the sequent(s) above that line have a proof. Here it is useful to distinguish between provisional (or tentative) and successful applications of an inference rule (thema). Until a full proof of a sequent has been constructed, every use of an inference rule starting from that sequent is provisional only. This can be indicated by a question mark after the added name of the thema, e.g. 'T1?'. Once the sequent has been proved, the question marks can be deleted. Consecutive applications of the themata are possible, with the premise(s) of one application becoming the conclusion of another, resulting in larger binary trees.

\section{Axioms (Indemonstrables)}

Indemonstrables (anapodeiktoi) are the basic formally valid two-premise arguments from which the non-basic formally valid arguments are composed and into which they can be analysed. This marks them out as essential parts of the Stoic deductive system: they are its axiomatic sequents or axioms. The Stoics distinguish five kinds of axioms. An axiom of the first kind is a first indemonstrable, one of the second kind a second indemonstrable, and so on. Each kind is given a definition in the Stoic logical meta-language. ${ }^{20}$ Within Stoic analysis, the definitions (AR1-AR5 below) can be regarded as axiomatic rules. By an axiomatic rule I understand a sentence functionally analogue to an axiom schema, but containing no (explicit) meta-variables or schematic letters and expressed in meta-language

\footnotetext{
${ }^{20}$ Cf. D.L.7.80-81, S.E.PH.2.157-9, S.E.M.8.224-7, Gal.Inst.Log.VI.6, [Galen] Hist.Phil.15. There are slight differences in formulation, but the elements that are of logical relevance are always present in the same way. (The passages Cicero Topics 54, Ammon.An.Pr.68.23-41, Philop.An.Pr.244-6, Anon.Heiberg.38, do not describe Stoic indemonstrables.)
} 
rather than object language. The definitions display the same precision and vocabulary as the formulations of the themata:

(AR1) A first indemonstrable is an argument that from a conditional and its antecedent deduces the consequent <of the conditional>.

(AR2) A second indemonstrable is an argument that from a conditional and the contradictory of the consequent deduces the contradictory of the antecedent < of the conditional>.

(AR3) A third indemonstrable is an argument that from the negation of a conjunction and one of the conjuncts deduces the contradictory of the other conjunct.

(AR4) A fourth indemonstrable is an argument that from a disjunction and one of the disjuncts deduces the contradictory of the other disjunct.

(AR5) A fifth indemonstrable is an argument that from a disjunction and the contradictory of one of its disjuncts deduces the other disjunct.

Every substantial expression in the definientia of AR1-AR5 is part of the Stoic logical metalanguage $(\S 1)$. In keeping with the formalization of the themata, I now substitute each metalinguistic rule by a meta-linguistic axiom schema of equal strength, where by a metalinguistic axiom schema I mean an axiom schema of a kind that may include symbols for meta-linguistic logical expressions in addition to its meta-variables. This involves replacing the meta-linguistic expressions in the definientia by the corresponding object language, (using the symbols introduced in $\S 1$ ); 'deduces' by ' $\vdash$ '; 'contradictory of' by the 
metalinguistic operator '*'; and using ',' to separate members of the antecedent, all as in the inference schemata for the themata: ${ }^{21}$

(A1)

$$
\mathrm{A} \rightarrow \mathrm{B}, \mathrm{A} \vdash \mathrm{B}
$$

$$
\mathrm{A} \rightarrow \mathrm{B}, \mathrm{B}^{*} \vdash \mathrm{A}^{*}
$$

$$
\neg\left[\mathrm{A}_{1} \wedge \mathrm{A}_{2}\right), \mathrm{A}_{\mathrm{i}} \vdash \mathrm{A}_{\mathrm{j}}^{*}
$$

$\mathrm{i}, \mathrm{j} \in\{1,2\}, \mathrm{i} \neq \mathrm{j}$

$$
A_{1} \oplus A_{2}, A_{i} \vdash A_{j}^{*} \quad i, j \in\{1,2\}, i \neq j
$$
$(\mathrm{A} 5)^{22}$
$\mathrm{A}_{1} \oplus \mathrm{A}_{2}, \mathrm{~A}_{\mathrm{i}}^{*} \vdash \mathrm{A}_{\mathrm{j}}$
$\mathrm{i}, \mathrm{j} \in\{1,2\}, \mathrm{i} \neq \mathrm{j}$

The horizontal line or end stroke above the sequent schema signifies that this is an axiom schema: a schema with a conclusion but no premises. The ingenuity of the Stoic choice of

${ }^{21}$ Given the proviso about negation in $\$ 1$, one of $\mathrm{A} 1, \mathrm{~A} 2$ is redundant in the sense that if removed, exactly the same sequents would have a proof. Here is not the place to discuss why the Stoics had both; they may have considered them both equally evident. Note that Gentzen's systems LK and LJ are redundant in a similar sense, cf. Gentzen 1934, pp. 193-4.

${ }^{22}$ There is evidence that Chrysippus may have recognized a special kind of fifth indemonstrable with several mutually exclusive disjuncts (S.E.P.H.1.69). The example suggests a form with three disjuncts, with $\mathrm{i}, \mathrm{j}, \mathrm{k} \in\{1,2,3\}, \mathrm{i} \neq \mathrm{j} \neq \mathrm{k}$ :

$$
\left(A 5^{3}\right) \quad A_{1} \oplus A_{2} \oplus A_{3}, A_{i}^{*} \wedge A_{j}^{*} \vdash \quad A_{k}
$$

By use of $\mathrm{T} 1, \mathrm{~A} 5^{3}$ yields the additional schema

$$
\left(\mathrm{A} 9^{3}\right) \quad \mathrm{A}_{\mathrm{i}}^{*} \wedge \mathrm{A}_{\mathrm{j}}{ }^{*}, \mathrm{~A}_{\mathrm{k}}{ }^{*} \vdash \neg\left(\mathrm{A}_{1} \oplus \mathrm{A}_{2} \oplus \mathrm{A}_{3}\right)
$$

It seems that three-disjunct indemonstrables as defined by $\left(\mathrm{A} 5^{3}\right)$ could be seamlessly integrated into Stoic sequent logic. Finite multiple-disjunct indemonstrables reopen the above question whether the Stoics had multi-conjunct conjunctions, although these would not be necessary. There is no evidence that Chrysippus, or any early Stoics, recognized multiple disjunct fourth indemonstrables (which they may well have had) or multiple conjunct third indemonstrables (which I am sceptical about), and I will not consider their possibility. There is evidently room for future research, and some considerations can be found in Jennings 1994, ch.10. 
axiomatic rules becomes evident when one considers that they had to be easily memorizable and usable without pen and paper or a computer: For pre-computer-age logicians who use memorization as a standard technique, the choice of the meta-linguistic AR1-AR5 is highly efficient. Recall that the Stoics had neither the terminology of set theory nor uniform substitution rules, that there is no evidence that double negation introduction and elimination were part of Stoic analysis ${ }^{23}$ and that commutativity was not built into conjunction and disjunction. Without these, AR1-AR5 had sixty-four object-language schemata to encompass. Perusal of AR1-AR5 shows that they leave the order of antecedent propositions in the sequents undetermined; that uniform substitution is covered, and that the use of 'contradictory' leaves it open which of the two contradictories, if any, is an affirmation - just as in T1. The use of 'one of the conjuncts/disjuncts' and 'the other conjunct/disjunct' instead of meta-variables also each 'saves' an object-language axiom schema. For example, with A1-A5, the sequent $\mathrm{q}, \neg \mathrm{p} \rightarrow \neg \mathrm{q} \vdash \mathrm{p}$ is an $\mathrm{A} 2$ axiom no less than $\mathrm{p} \rightarrow \mathrm{q}, \neg \mathrm{q} \vdash \neg \mathrm{p}$ or $\neg \mathrm{p} \rightarrow \neg \mathrm{q}$, $\neg \neg \mathrm{q} \vdash \neg \neg \mathrm{p}$; and $\mathrm{p} \oplus \mathrm{q}, \mathrm{p} \vdash \neg \mathrm{q}$ is an A4 axiom no less than $\mathrm{p} \oplus \mathrm{q}, \mathrm{q} \vdash \neg \mathrm{p}$.

It is then strictly speaking incorrect to represent the definientia of the five Stoic definitions as object-language axiom schemata, since they contain meta-linguistic expressions, that is, expressions which from a Stoic perspective are part of the meta-language they invoke to describe object-language arguments and their properties (cf. Becker 1957, Bobzien 1996). If one wishes to implement Stoic logic in, say, Prolog, such adjustments can, of course, be made. Once, as chosen here, one formalizes the five definientia in Stoic-derived metalanguage, it is innocuous to think of the resulting A1-A5 as metalinguistic axiom schemata. (This requires a definition of the operator ' $*$ ' in terms of negation - e.g. as given in $\S 1$.)

\footnotetext{
${ }^{23}$ Pace Milne 2012. Note that, as suggested in $§ 3$, the first thema already covers negation, including double negation.
} 
Where 'axiom schema' is used below, it is in this meta-linguistic sense. The Stoics used their term for 'axiom' (anapodeiktikos) only for indemonstrables. Accordingly, I reserve the term 'axiom' for object-language sequents, thus retaining the distinction between the infinitely many Stoic indemonstrables (axioms) and the five definientia of their five kinds (metalinguistic axiom schemata). ${ }^{24}$

Application of the axiom schemata in proof search: We can relate A1-A5 more specifically to Stoic proof search as a directional process. Extant examples show that a proof search terminates with a proof when the inference rules have yielded axioms and no antecedent formulae are left. The axioms are the endpoints of a Stoic proof search. When they are reached, or in tree terms, once there are only axioms as leaves, we have a proof. A1-A5 determine whether a branch is closed, and if yes, what kind of axiom we have as leaf. Once an inference rule yields an axiom as a premise, no further inference rule can be applied to that branch: In a Stoic proof search, A1-A5 function as end schemata. Whereas 'axiom schema' and 'axiomatic rule' are non-directional terms that apply to proofs, 'end schema' indicates the direction in which the proof search runs. (In a Stoic proof search the first step would check whether the end sequent is itself an axiom.) In order to indicate that a proof search, or part of one, is completed with an axiom by use of an axiom schema as end schema, I put a horizontal line or end stroke above the axiom, with $\mathrm{A} 1, \mathrm{~A} 2, \ldots$ next to the line to indicate the kind of axiom. Such a line signifies that an axiomatic sequent has been reached:

\section{$\overline{\mathrm{p}, \mathrm{p} \rightarrow \neg \mathrm{q} \vdash \neg \mathrm{q}}$}

\footnotetext{
${ }^{24}$ Thus it is unhelpful to call the argument schemata that correspond to the Stoic definitions axioms, as is sometimes done. In Stoic sources, 'indemonstrable' never denotes an argument schema. Although some later ancient, and most contemporary, philosophers refer to 'the five Stoic indemonstrables' and identify these with five object-language argument schemata, this is at best imprecise.
} 
$\mathrm{p}, \mathrm{q} \vdash \neg(\mathrm{p} \rightarrow \neg \mathrm{q})$

Similar to their distinction between simple propositions (literals) and non-simple ones, as contrasted with atomic and molecular ones, the Stoics appear to have distinguished simple and non-simple sequents (arguments), as contrasted with axiomatic and non-axiomatic ones: ${ }^{25}$ Just as, unlike the non-simple propositions, the simple ones are not composed from several (occurrences of) propositions, so unlike the non-simple sequents, the simple ones are not analysed into several (occurrences of) axioms. Whether or not the Stoics themselves introduced this distinction, it is useful to present their logic. There are four meta-logical nonaxiomatic simple sequent schemata. These can be analysed into axioms in cut-free proofs by one use of T1:

$$
\mathrm{A}, \mathrm{B}^{*} \vdash \neg(\mathrm{A} \rightarrow \mathrm{B}) \quad \text { (sequents analyzable into A1 or A2 axioms) }
$$

$\mathrm{A}, \mathrm{B} \vdash \mathrm{A} \wedge \mathrm{B}$

(sequents analyzable into A3 axioms)

$\mathrm{A}, \mathrm{B} \vdash \neg(\mathrm{A} \oplus \mathrm{B})$

(sequents analyzable into A4 axioms)

$$
\left.\mathrm{A}^{*}, \mathrm{~B}^{*} \vdash \neg(\mathrm{A} \oplus \mathrm{B}) \quad \text { (sequents analyzable into A5 axioms) }\right)^{26}
$$

\footnotetext{
25 'Appear', since the text is not absolutely unequivocal. Simple arguments are said to be 'those in which it is immediately clear that they are valid, that is that they introduce their conclusion together with the assumptions' (S.E.M.8.228). 'Non-simple <formally valid arguments> are those that are composed (braided together) from simple ones and that need an analysis into these <simple ones> in order for us to be able to know that they, too, are valid.' (S.E.M.8.228-9). The use of the singular 'analysis' and the plural reference to simple arguments that are braided together ('into these'), the repeated use of the expression 'braided together' and the subsequent presentation of examples for non-simple arguments (S.E.M.8.229-234) suggest the reading here adopted. The Stoic distinction between indemonstrables and arguments analysable into indemonstrables (D.L.7.78) then differs from that between non-simple and simple syllogisms (S.E.M.8.229): Some non-indemonstrable syllogisms are simple, namely those whose demonstration is a one-step reduction, using the first thema, to an indemonstrable. (In either reading of the passage, S.E.M.8.228 'indemonstrable' must be an error. It should read 'syllogism'.)

${ }^{26}$ Negation is used in A6, A8, A9 instead of '*', since the contradictory of an affirmation always is its negation. Since the antecedent propositions are not ordered, there is no need for the subscript letters i and $\mathrm{j}$.
} 
There are, then, nine simple sequent schemata altogether, not counting substitution instances.

\section{Examples of Stoic Proof Search and Formalization of Stoic Analysis}

We can now formally represent instances of the Stoic method of proof search. In terms of trees, T1-T4 and A1-A5 generate proofs as root-to-leaves unary or binary trees with the end sequent as root and axioms as leaves. The structural rule Permutation $(\Gamma, \mathrm{A}, \mathrm{B} \vdash \mathrm{C} \Rightarrow \Gamma, \mathrm{B}, \mathrm{A}$ $\vdash \mathrm{C}$, see §7) permeates the nine Stoic logical rules: each is fastidiously worded so that the order of the antecedent formulae is undetermined. (This is one of my reasons for interpreting the antecedents of Stoic sequents as -single- multisets in multiset notation.)

No full description of an instance of proof search survives. We do have a partial description (S.E.M.8.229-35). It provides two instances of Stoic analysis intended to illustrate (i) nonsimple syllogisms composed from two axioms of different kinds, and (ii) non-simple syllogisms composed from two axioms of the same kind. A complete instance of analysis would include a mention of what themata are used where in the proof search, in addition to what axioms a syllogism is composed of. ${ }^{27}$ The two examples illustrate how Stoic proof search runs from the end sequent to the axioms and terminates successfully when the end sequent has been analysed in its entirety into axioms. The example of an analysis into axioms of different kinds has this end sequent:

$$
5.1 \quad(\mathrm{p} \wedge \mathrm{q}) \rightarrow \mathrm{r}, \neg \mathrm{r}, \mathrm{p} \vdash \neg \mathrm{q} .
$$

\footnotetext{
${ }^{27}$ Passages that mention the thema(ta) used in a proof are e.g. D.L.7.78, Apul.Int.191.6-10, Alex.An.Pr.164, 274.11-14, 284, Simpl.Cael.237.2-4, Gal.Plac.Hipp.Plat.2.3.18-19; cf. Bobzien 1996, pp. 142-71.
} 
Its axioms are of the kinds A2 $((\mathrm{p} \wedge \mathrm{q}) \rightarrow \mathrm{r}, \neg \mathrm{r} \vdash \neg(\mathrm{p} \wedge \mathrm{q}))$ and A4 $(\neg(\mathrm{p} \wedge \mathrm{q}), \mathrm{p} \vdash \neg \mathrm{q})$. The search involves one application of T3:

$\begin{array}{llll} & & \text { A2, A3 } \\ \text { (2) } & (\mathrm{p} \wedge \mathrm{q}) \rightarrow \mathrm{r}, \neg \mathrm{r} \vdash \neg(\mathrm{p} \wedge \mathrm{q}) & \neg(\mathrm{p} \wedge \mathrm{q}), \mathrm{p} \vdash \neg \mathrm{q} & \\ & & \mathrm{T3}\end{array}$

In this representation, the expressions to the right at the level of each horizontal line denote the schemata used. The line numbers to the left in the derivation are added for purposes of reference only, and as a reminder that the proof search is backward. The example that analyses an end sequent into two axioms of the same kind has as end sequent:

$$
\mathrm{p} \rightarrow(\mathrm{p} \rightarrow \mathrm{q}), \mathrm{p} \vdash \mathrm{q}
$$

Its axioms are of the kind A1. The proof search applies T2 once:

A1, A1

$\mathrm{T} 2$

(1) $\quad p \rightarrow(p \rightarrow q), p \vdash q$

A Stoic proof search can involve more than one inference schema (D.L.7.78, Gal.Plac.Hipp.Plat.2.3.18-19). Take this sequent, which the Stoics consider valid.

\section{$5.3 \mathrm{p} \rightarrow \mathrm{q}, \mathrm{r} \rightarrow \mathrm{q}, \mathrm{p} \oplus \mathrm{r} \vdash \mathrm{q}$}


Here is a tree representation of the proof search for 5.3 in seven steps, that is, with seven schema applications.

(5)

\begin{tabular}{|c|c|c|c|}
\hline & & $\mathrm{p}, \mathrm{p} \rightarrow \mathrm{q} \vdash \mathrm{q}$ & \\
\hline & $\mathrm{p} \oplus \mathrm{r}, \neg \mathrm{r} \vdash \mathrm{p}$ & $\mathrm{p}, \neg \mathrm{q} \vdash \neg(\mathrm{p} \rightarrow \mathrm{q})$ & \\
\hline $\mathrm{r} \rightarrow \mathrm{q}, \neg \mathrm{q} \vdash \neg \mathrm{r}$ & $\mathrm{p} \oplus \mathrm{r}, \neg \mathrm{r}, \neg \mathrm{q} \vdash \neg(\mathrm{p} \rightarrow \mathrm{q})$ & & \\
\hline $\mathrm{r} \rightarrow \mathrm{q}, \mathrm{p} \oplus \mathrm{r}, \neg \mathrm{q}$ & $\rightarrow q)$ & & \\
\hline
\end{tabular}

Stoic analysis allows for different proofs, possibly of different length and depth, for the same end sequent (see also below).

In the remainder of this section I ignore differences between the five axiom schemata and between the three cut schemata and consider more generally what kind of deductive method Stoic analysis is, by comparing it with late $19^{\text {th }}$ to early $21^{\text {st }}$ century deductive methods for propositional logics. This comparison lays the ground for a full formalization of Stoic propositional logic.

Above I said that the Stoics used the term 'analysis' both for their general method of proof search and for instances of its application. We can now be more specific. The proof search is proof search by proof construction. ${ }^{28}$ That is, whenever a search for a proof of a sequent has been successful - when we have an instance of an analysis - a proof of that sequent has been

28 'Proof construction' is here used in a non-technical way, as the process of building a proof (or derivation) in accordance with the rules of the logic. 
constructed. I have represented these proofs as tree diagrams for sequents. This is borne out by the Stoic examples of analysis and their formulations of the inference rules. The proof construction is a process, and as such is, in lack of a better word, directional. It works from the root to the leaves, as it were. The so constructed proof is an object. Its structure is nondirectional. The tree diagrams can be understood both as representing the proof search by proof construction (working from root to leaves) and as representing the resultant nondirectional proof (which can be read whichever way one pleases). In the first case, the nine Stoic rules of analysis are directional; in the second, they are not. There is no specific term used by the Stoics for the proofs (the objects) that are constructed by their method of proof search. ${ }^{29}$ There are then two ways of looking at Stoic logic: first, as the directional backward proof-search method in line with its description in the surviving examples that is Stoic analysis; second, as the (non-directional) system of an indefinite number of proofs expressible in tree form, with axioms as leaves, premises and conclusions of T1-T4 applications as nodes, and in line with the Stoic claim that deductively valid sequents (syllogisms) are composed of axioms (indemonstrables).

Next, compare Stoic analysis and the Stoic proof system with contemporary propositional logics by means of a number of familiar parameters. (i) Stoic analysis is a sequent method of presenting logic, not a typical propositional or sentential Frege-Hilbert-style method (e.g. Frege 1879, Hilbert 1922, 1923). Sequent methods (e.g. Gentzen 1934, Smullyan 1968) prove the validity of sequents and their axioms and theorems are sequents. (ii) Stoic analysis is a single-succedent sequent method (like Gentzen's 1934 calculus LJ, Smullyan 1968), not a multiple-succedent method (like Gentzen's 1934 calculus LK). (iii) Stoic analysis is not a

\footnotetext{
${ }^{29}$ The Stoic terms 'syllogism', 'indemonstrable' and 'demonstration' (D.L.7.45, see above fn 12) all denote arguments, which here correspond to sequents. Arguments are objects, not processes. Syllogisms are said to deduce (sunagein) their conclusion. Such a deduction is a relation between (the single multiset of) antecedent propositions and the succedent proposition.
} 
suppositional method. Suppositional methods (e.g. Gentzen's natural deduction calculus NJ, Jaskowski 1934) permit the introduction of sentences as assumptions that are discharged at some later point in the proof. Non-suppositional methods (e.g. Gentzen LK) do not. (iv) At the representational level, Stoic analysis corresponds best to a tree method, not a tabular one. Tabular or linear methods produce proofs in linear form (e.g. Kleene 1952), tree methods produce proofs in tree form (e.g. Gentzen 1934 LJ, LK, Smullyan 1968). The tree representation is the most natural way of reflecting the Stoic cut rules, and it can be done without introducing - much- additional terminology of which we have no Stoic counterparts. That said, linear representation of Stoic proofs is possible. (v) Stoic analysis is an unmediated method, not a mediated one. Unmediated methods have the demonstrandum as part of the tree (as e.g. Gentzen LJ) or table, mediated methods do not. Instead they use a meta-theorem as a bridging device between proof and demonstrandum (as e.g. Smullyan's 1968 sequent tableaux). Gentzen's sequent calculus LJ is an example of a system that combines the five features just identified as Stoic. There are two notable differences to Gentzen-style sequent calculi. (vi) Whereas Gentzen has right and left introduction rules for all connectives, in Stoic propositional logic this duality of rules is lacking: It has, in effect, only a right rule for conjunction, and only left rules for its disjunction and conditional (see also below §7). (vii) Related, in Gentzen's LK and LJ the Bedeutungen of the logical constants are absorbed in what he calls Schemata für Logische-Zeichen-Schlussfiguren, (Gentzen 1934, III.1.22), that is, inference schemata with logical constants. By contrast, in Stoic analysis, most of the logical structure is generated by the axiomatic rules (or schemata). This puts them closer to Hilbert-style systems, or in sequent logics to Gentzen 1933 or to Kleene's axiom schema (Kleene 1952, §23). ${ }^{30}$

\footnotetext{
${ }^{30}$ There are further similarities between the Stoic proof system and Gentzen's logic LJ. In both cases, some of the inference principles are redundant and could be covered by a combination of some of the others (Gentzen 1934, III.2.1). The analogues to Gentzen's initial sequents (Gentzen 1934, III.1.2) are
} 
The Stoic proof system differs from Gentzen's 1934 sequent calculi also in the way deduction principles are expressed. Where the Stoics have meta-linguistic natural-language rules, Gentzen employs three kinds of schematic principles: operational rules, i.e. the abovementioned object-language inference schemata that include logical constants; structural rules, i.e. object-language inference schemata that do not include logical constants; and one object-language schema for the initial sequents of a derivation (' $\mathcal{D} \vdash \mathfrak{D}$, where $\mathscr{D}$ may be an arbitrary formula' Gentzen 1934, III.1.2), sometimes called the Identity Axiom. This schema is structural in the sense that it does not contain logical constants. By analogy with Gentzen's structural and operational schemata, in Stoic logic one can distinguish between structural and operational rules. The cut rules T2-T4 are structural. The rule of contraposition T1 defies Gentzen's distinction, since it uses the Stoic meta-linguistic expression 'contradictory' instead of the object language negation operator. ${ }^{31}$ If meta-linguistic reference to logical constants is included, T1 is an operational rule. The Stoic A1-A5 correspond functionally to Gentzen's schema for initial sequents, except (i) that they contain logical constants (see above), which makes them operational, and (ii) that like T1, four of them use the metalinguistic notion of complement. It is also worth noting that Gentzen axiomatic sequents of

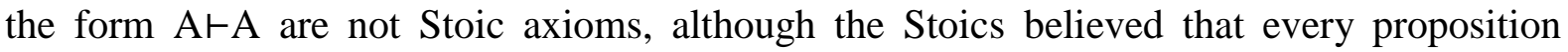
follows from itself. ${ }^{32}$

the indemonstrables: Like the latter, they can be considered as the axioms of the system and the number of axioms is infinite.

${ }^{31} \mathrm{~T} 1$ could be spelt out using four object-language operational rules in the obvious way. But this is not what the Stoics do. They have economical reasons to choose the one meta-linguistic rule over several object-language rules. (The case is analogous to the choice of meta-linguistic axiom schemata.)

${ }^{32}$ Cf. Cicero Acad. 30, S.E.M.8.281 and 466. The Stoic term for 'follows from' is akolouthein. Similar to Russell, the Stoics hold both that a conditional is true, when the consequent follows from the antecedent, and that a Stoic argument is valid, when the conclusion follows from the conjunction of its assumptions. Although the consequence relation (akolouthia) between $A$ and itself is formal, ' $A$ 
The sequent proofs themselves are structurally no different, whether their principles are given meta-linguistically or as object-language schemata. So the Stoic proof system can be represented formally in the same ways as Gentzen-style systems, which I do next. Essentially, at this point all that is lacking for a full formalization is a formal definition of a proof tree (a tree that represents a proof). Take the logical syntax from $\S 1$, including the syntactic constraints on sequents. Add T1-T4 and A1-A5 from $\S \S 3-4$. Complement these with the following two definitions. The first defines a Stoic proof tree $:^{33}$

5.4 Let $\Sigma$ be a Stoic sequent. A Stoic proof tree T for $\Sigma$ is a finite tree whose root (end sequent) is $\Sigma$ and every node $\Sigma_{\mathrm{i}}$ in $\mathrm{T}$ is either a leaf or it is the conclusion of an inference schema instance of the Stoic deduction system, where the premises are the nodes (the premise is the node) in T immediately above $\Sigma_{\mathrm{i}}$.

Here, every sequent is a node, a leaf is any sequent with no node above it and a root is any sequent that has no sequent below it. Based on the definition of a Stoic proof tree, we can define a Stoic sequent proof (or a Stoic derivation) thus:

5.5 A Stoic proof tree T over a Stoic sequent $\Sigma$ is a Stoic sequent proof if all the leaves of $\mathrm{T}$ are axioms (i.e. indemonstrables).

This shows that Gentzen-style tree-form representation of a propositional logic captures the Stoic proof system well.

$\vdash A^{\prime}$ is not a provable sequent, since it has only one antecedent formula. See also Bobzien 1996, pp.183-4.

${ }^{33}$ The corresponding section in Gentzen 1934 would be I.3.2. 


\section{The Directionality in Stoic Proof Construction}

Stoic analysis differs from Gentzen's 1934-35 calculi also with regard to the process of proof construction. A main way in which Stoic proof search contrasts with Gentzen's is their directionality. For both Gentzen and the Stoics a proof is non-directional: What corresponds to the -constructed- proofs in each theory, i.e. derivations (Gentzen 1934, I.3.2) and Stoic sequent proofs, are in each case independent of whether one considers a proof tree root-first or leaves-first. However there is evidence that Gentzen himself conceived of the construction process of his proofs in tree form in a directional manner, from leaves to root. This is hinted at by the facts that he calls the basic sequents that correspond to proof leaves initial sequents (Gentzen 1934, III.1.2), the tree root end formula (ibid. I.3.2.) and the leaves generally initial formulae (ibid. I.3.3). Clear evidence is provided in Gentzen's application of the Hauptsatz to propositional logic, in the description of the decision procedure (Gentzen 1935, IV.1.23). ${ }^{34}$

Nowadays, it is generally acknowledged that proof search in Gentzen-style calculi can be either forward (leaves-first) or backward (root-first). ${ }^{35}$ Backward proof search applies the rules of the proof system 'backwards' or 'bottom-up', working from the root to the leaves, just as the informal procedure of Stoic analysis described in $\S \S 3-5$. In systems of automated theorem proving, interactive theorem proving, and logic programming the backward style is prevalent. For example Patrick Lincoln, in his overview of certain substructural logics, writes

\footnotetext{
${ }^{34}$ The objection that Gentzen's use of 'Verdünnung' suggests otherwise does not hold up, since the German word (as the English 'thinning') can mean both 'thinning out' and 'diluting', and is not decisive on the question.

35 The introduction of backward proof construction in sequent logic, called Dekomposition (decomposition), seems to go back to Ketonen 1944 (summarized in Bernays 1945). Backward proof search is the traditional direction for sequent calculi, see. e.g. Troelstra and Schwichtenberg 1996, Negri and von Plato 2001, Dyckhoff and Negri 2012; and in automated theorem proving, see e.g. Graham-Lengrand 2013.
} 
"we will usually be speaking informally of a computational process searching for a proof of a formula from the bottom up in a sequent calculus. Thus given a conclusion sequent, we attempt to find its proof by trying each possible instance of each sequent proof rule. This point of view directly corresponds to the computational model of logic programming." (Lincoln 1995, 110). It appears that Stoic analysis shares the objective of backward proof search with such systems. This is no surprise, since it is easier to search for a Stoic sequent proof 'manually' backwards (cf. e.g. Bobzien 1996, pp. 160-1, fn.34), just as it is generally easier for a proof-search engine.

The Stoic backward use of a rule can be described more formally as follows. It works from conclusion sequents to premise sequents. It is assumed that the sequent $\Sigma$ whose provability is to be tested is provable, say

$$
\Gamma \vdash B \quad \text { with } A_{i}, A_{j} \in \Gamma \text { and } A_{i} \neq A_{j}
$$

On that assumption (which may of course turn out false) either $\Gamma \vdash \mathrm{B}$ is an axiom or $\Gamma, \mathrm{B}^{*} \vdash$ $\mathrm{A}_{\mathrm{i}}{ }^{*}$ is provable, or there is a cut formula $\mathrm{C}$ such that

either $A_{i}, A_{j} \vdash C$ and $C, A_{i} \vdash B$ are provable

or $A_{i}, A_{j} \vdash C$ and $C, A_{i}, A_{j} \vdash B$ are provable

or $\mathrm{A}_{\mathrm{i}}, \mathrm{A}_{\mathrm{j}} \vdash \mathrm{C}$ and $\mathrm{C}, \Gamma /\left\{\mathrm{A}_{\mathrm{i}}, \mathrm{A}_{\mathrm{j}}\right\} \vdash \mathrm{B}$ are provable (T3)

or $\mathrm{A}_{\mathrm{i}}, \mathrm{A}_{\mathrm{j}} \vdash \mathrm{C}$ and $\mathrm{C}, \Gamma\left(/\left\{\mathrm{A}_{\mathrm{i}}\right\}\right) \vdash$ are provable

or $\mathrm{A}_{\mathrm{i}}, \mathrm{A}_{\mathrm{j}} \vdash \mathrm{C}$ and $\mathrm{C}, \Gamma \vdash$ are provable

A rule is then chosen in which $\Sigma$ is placed as the conclusion sequent. Depending on choice of rule, an end stroke (in the cases A1-A5) or an inference stroke followed by a relevant premise 
(in case T1) or relevant premises (for T2-T3), are added above the conclusion. ('above' because of the presentational convention introduced earlier.) Where $\Sigma$ is an instance of A1A5 this fact is easily recognizable. In the case of the T1-T4, the premises obtained by the backward use of the rule are in turn treated as conclusion or conclusions, respectively, and the procedure is repeated. Thus, the backward use of an inference rule always consists of working from the conclusion via the rule to the premise or premises, and on the provisional-assumption that the conclusion is provable. ${ }^{36}$

So, Stoic proof search can be understood as an informal method of backward Gentzen-style proof search by proof construction and Stoic logic as a backward Gentzen-style propositional sequent logic of proof search by proof construction. Why the suggestion that Stoic logic itself is directional? First, because the objects of Stoic logic (the proofs) have no name and never occur separately from the analysis of their end sequent, so there is reasonable doubt whether they were an explicit part of Stoic theory. Second, if Stoic logic was non-directional, it would be far less good, as we will see.

The backward directionality of Stoic proof search is quite compatible with the assumption that the Stoics collected theorems of their system. There is actually evidence that they had theorem rules, called theorems (theōrēmata), which describe the forms of certain derivable sequents (Origen Cels.166, cf. S.E.P.H.2.3). In keeping with their rule-based sequent logic, these theorems are expressed meta-linguistically and in natural language rather than as theorem schemata. An example is the theorem by means of two mode-forming

\footnotetext{
${ }^{36}$ For a contemporary example of such backward rule use in a derivation see e.g. Troelstra and Schwichtenberg 1996, 109-111.
} 
$\left\langle\right.$ propositions $>{ }^{37}$ : 'when two conditionals share the same antecedent and have consequents that are contradictories of each other, then the antecedent is removed (anhairetai). ${ }^{38} \mathrm{We}$ can conjecture that whenever a sequent of the relevant form is considered, or reached, as part of a proof search, such theorems could have been appealed to directly as a way of completing the proof in abbreviated form (cf. Frede 1974). Thus, in a Stoic proof search, such theorems could have been considered as abbreviatory rules similar e.g. to Kleene's 'direct rules' (Kleene 1952, p. 86).

For Gentzen calculi it is generally irrelevant whether proofs are constructed leaves-first or root-first. They can even be started at both ends. This is not so in Stoic 'proof theory'. Derivations can only be constructed root-to-leaves. The method is strictly analytical. In certain cases it would make a difference in provability if derivations were constructed leavesfirst. The reason is a combination of two factors: the constraint that the cardinality of the

\footnotetext{
${ }^{37}$ A mode-forming (tropikon) proposition is any Stoic non-simple proposition such that, if one of its four immediate \pm subformulae is added, an axiom can be constructed. Such propositions are conditionals, disjunctions and negations of conjunctions (Gal.Inst.Log.7.1, Bobzien 1996, p. 136).

${ }^{38}$ The 'antecedent is removed': that is, its negation can be concluded. Here is the proof of an instance of the theorem.
}

(4)

$$
\overbrace{\mathrm{p} \rightarrow \neg \mathrm{q}, \mathrm{p} \vdash \neg \mathrm{q}} \quad \frac{\neg \mathrm{q}, \mathrm{p} \rightarrow \mathrm{q} \vdash \neg \mathrm{p}}{\neg \mathrm{q}, \mathrm{p} \vdash \neg(\mathrm{p} \rightarrow \mathrm{q})}
$$

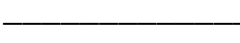

$$
\mathrm{p} \rightarrow \neg \mathrm{q}, \mathrm{p} \vdash \neg(\mathrm{p} \rightarrow \mathrm{q})
$$

$$
\mathrm{p} \rightarrow \mathrm{q}, \mathrm{p} \rightarrow \neg \mathrm{q} \vdash \neg \mathrm{p}
$$

Substitution may appear problematic, but it is not. Substitution in (1) of $\neg$ q for p uses $\mathrm{T} 1(\neg \mathrm{q} \rightarrow \neg \mathrm{q})$, $\mathrm{T} 2(\neg \mathrm{q}), \mathrm{A} 1, \mathrm{~T} 1, \mathrm{~A} 1$ or A2. Substitution of $\mathrm{q}$ for $\mathrm{p}$ uses $\mathrm{T} 1(\mathrm{q} \rightarrow \mathrm{q}), \mathrm{T} 2(\mathrm{q}), \mathrm{A} 1, \mathrm{~T} 1, \mathrm{~A} 1$ or A2. 
antecedent is at least two and the fact that Stoic antecedents are like single multisets in multiset notation in that each proposition can be listed only once $(\S 1)$.

Stoic analysis tests whether a sequent has a proof, starting with the end sequent. Root-first, any use of rules T1-T4 yields from one conclusion one or two Stoic sequents as premises. This is evident from the formulations of the rules. In contrast, the specification of these rules renders it uncertain how they are to be applied in leaves-first use in a way that ensures that the conclusion is a sequent. The directionality in Stoic proof construction affects simple sequents of four forms: the forms which result from substituting A for B (or B for A) in the schemata A6-A9 (above, §3), resulting in schemata:

$\begin{array}{ll}\left(\mathrm{A}^{\prime}\right) & \mathrm{A}, \mathrm{A} \vdash \neg(\mathrm{A} \rightarrow \neg \mathrm{A}) \\ \left(\mathrm{A} 7^{\prime}\right) & \mathrm{A}, \mathrm{A} \vdash \mathrm{A} \wedge \mathrm{A} \\ \left(\mathrm{A} 8^{\prime}\right) & \mathrm{A}, \mathrm{A} \vdash \neg(\mathrm{A} \oplus \mathrm{A}) \\ \left(\mathrm{A} 9^{\prime}\right) & \neg \mathrm{A}, \neg \mathrm{A} \vdash \neg(\mathrm{A} \oplus \mathrm{A}) .\end{array}$

A leaves-first method could derive sequents of these forms from A1-A5, with suitable substitution and one use of T1. For example, $\neg(\mathrm{p} \wedge \mathrm{p}), \mathrm{p} \vdash \neg \mathrm{p}$ is an A1 axiom, and T1, applied leaves-first, yields:

$$
6.1 \quad \mathrm{p}, \mathrm{p} \vdash \mathrm{p} \wedge \mathrm{p} \text {. }
$$

But (6.1) is not a Stoic sequent since it is ill-formed. The other three cases are similar. Additionally, there are some non-simple sequents, of the forms $A, A \vdash \neg(A \rightarrow(A \oplus A))$ and generally $\mathrm{A}, \mathrm{A} \vdash \neg(\mathrm{A} \rightarrow(\mathrm{A} \rightarrow(\mathrm{A} \rightarrow(\mathrm{A} \rightarrow \ldots(\mathrm{A} \oplus \mathrm{A})))))$; and $\mathrm{A}, \mathrm{A} \vdash \neg(\mathrm{A} \rightarrow(\mathrm{A} \rightarrow \neg \mathrm{A}))$ and 
generally $\mathrm{A}, \mathrm{A} \vdash \neg(\mathrm{A} \rightarrow(\mathrm{A} \rightarrow(\mathrm{A} \rightarrow(\mathrm{A} \rightarrow \ldots(\mathrm{A} \rightarrow \neg \mathrm{A}))))) .{ }^{39}$ These would be the result of illicit forward use of $\mathrm{T} 1$ on provable sequents whose proofs require uses of $\mathrm{T} 2$ in increasing number.

This shows that the Stoic proof system when coupled with leaves-first proof construction becomes problematic: it allows the derivation of ill-formed expressions. Yet, for all we know, Stoic logic does not involve leaves-first proof construction. Consequently, since the input expressions must be Stoic sequents and (6.1) (and the analogues for A6' A8' A9' and the nonsimple sequent schemata just mentioned) are not Stoic sequents, no problem arises. Unlike in Gentzen systems, root-first directionality is an integral part of the Stoic proof system. The fact that if used leaves-first on suitable axioms, T1 would yield expressions of the forms $\mathrm{A} 6^{\prime}-\mathrm{A} 99^{\prime}$, etc. is thus no evidence that the Stoics had sequents with two identical assumptions. Since Stoic analysis does not actually yield such expressions, we also have no counterexample to the interpretations of the antecedents of Stoic sequents either as single multisets or as sets.

\section{Stoic Analysis and Substructural Logics}

The Stoic deductive system is not equivalent to classical propositional logic. This is already obvious from two facts stated in previous sections. First, there are structural constraints on the number of antecedent and succedent formulae in a sequent. As a result we can at most have a fragment of classical propositional logic. Second, only the axiomatic rule A3 would correspond directly to axiomatic sequents for classical logic, since only negation and conjunction have a truth-functional semantics. The semantics of the connectives for

\footnotetext{
${ }^{39}$ The Stoics may have discussed recursively defined propositions like those schematically described in the bracket after the succedent's negator, cf. Bobzien 1996, pp. 170-71.
} 
disjunction and conditional is based on the modal term 'conflict' (makhē) and is stronger than classical semantics. ${ }^{40}$ This notwithstanding, if a Stoic sequent is provable, then its classical analogue (with classical, i.e. material, conditional and exclusive disjunction) is provable in classical logic, though the reverse does not hold. ${ }^{41}$ There is a further discrepancy, one that is connected with the Stoic method of analysis, to which I turn in this section.

Like all known ancient deductive systems, the Stoic system is a substructural logic, ${ }^{42}$ more precisely, a kind of relevance logic: The system lacks Thinning and contains as analogue to a variable sharing principle the following principle

A sequent is provable only if the antecedent and consequent share at least one atom(ic formula).

A proof of this Stoic principle has been given in Bobzien \& Dyckhoff (forthcoming). For now I bypass the question how exactly Stoic logic compares to contemporary systems of propositional relevance logic. (I return to it briefly at the end of the section.) There is a set of issues that is more closely related to the method of analysis. We saw that Stoic analysis is best understood as a backward Gentzen-style propositional sequent logic. Now, in addition to logical principles and a cut rule, standard representations of Gentzen's calculi LJ and LK have a uniform substitution rule, or alternatively theorem schemata, and the structural rules

\footnotetext{
40 'Stronger' in the sense in which strict implication is stronger than material implication. Chrysippus' conditional is however not the same as strict implication, but closer to McCall's connexive implication. The details are irrelevant here. Cf. Kneale and Kneale 1962, pp. 160-61, Frede 1974, pp.82-7, 95-6, Bobzien 1999, pp. 106-10, Milne 2012, p. 15.

${ }^{41}$ Assuming a suitable translation, we can represent Stoic logic as a fragment of classical logic, since there are classical formal analogues to all rules and axiom schemata.

${ }^{42}$ A substructural logic is a logic that lacks one or more of the standard structural rules (usually) of classical or intuitionistic logic. Standard examples are relevance logic, linear logic and the Lambek calculus. For an introduction to substructural logics see e.g. Restall 2000.
} 
Permutation, Contraction and Thinning. For the Stoics, no such rules are mentioned, let alone survive. As will become clear, there is also no substantial logical reason for assuming that in addition to A1-A5 and T1-T4 they had explicit formulations of any of these rules. The questions examined in this section are if, in which way, and how far substitution and those three structural rules were accounted for in Stoic analysis. Remember that as part of Stoic proof construction, Contraction, Thinning and Permutation would have to be employed 'backward', just like the other Stoic rules (see §6): They would be applied on a formula qua conclusion and they yield a premise, and they sanction that backward step only if the conclusion is provable.

Permutation. We have seen in $\S \S 2-5$ that Permutation is preserved by the careful phrasing of the nine rules: it is an admissible rule in the Stoic system that is absorbed in the Stoic rules. (By an admissible rule I mean a rule that can be omitted without any impact on which sequents are provable in the system.)

Contraction is admissible in Stoic analysis. In backward proof construction, Contraction sanctions the backward step from the conclusion $\Gamma, \mathrm{A}, \mathrm{A} \vdash \mathrm{B}$ to the premise $\Gamma, \mathrm{A} \vdash \mathrm{B}$ iff $\Gamma$, A, A $\vdash \mathrm{B}$ is provable. (Until a proof is constructed, as with all other backward applications of rules, application of Contraction is provisional only.) Now, no sequent $\Gamma, \mathrm{A}, \mathrm{A} \vdash \mathrm{B}$ is a Stoic sequent, which is to say, no such sequent is well-formed in the Stoic system. A fortiori no such sequent is a provable Stoic sequent. Hence, given that Stoic analysis is backward proof construction, Contraction finds no application and is trivially admissible.

Used forwards, from premise to conclusion, Contraction would produce ill-formed expressions, and would not be admissible. This notwithstanding, for many classical uses of 
Contraction in proof search, Stoic logic contains alternatives. One can show that any Stoic sequent that -with the antecedent-constraint revoked- is provable via Cut followed by Contraction can -with the constraint- be proven directly by $\mathrm{T} 2$ or T4. With $\Gamma=\Gamma^{\prime} \cup \Gamma^{\prime \prime}$ :

$\Gamma^{\prime}, \mathrm{A} \vdash \mathrm{C} \quad \mathrm{C}, \Gamma^{\prime \prime}, \mathrm{A} \vdash \mathrm{B}$

$\Gamma, \mathrm{A}, \mathrm{A} \vdash \mathrm{B}$

$\Gamma, \mathrm{A} \vdash \mathrm{B}$

Contraction

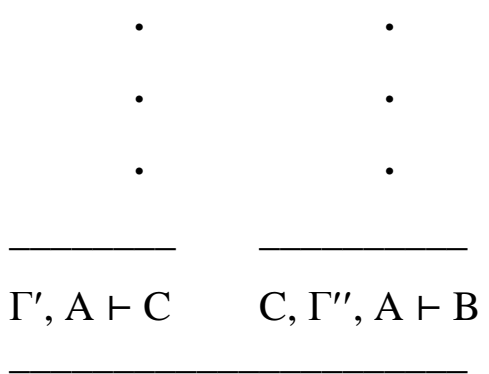

$\mathrm{T} 2$ or $\mathrm{T} 4$

$\Gamma, \mathrm{A} \vdash \mathrm{B}$

In effect, from a modern perspective one can think of the differentiation of the Stoic cut rules as $\mathrm{T} 2$, $\mathrm{T} 3$ and $\mathrm{T} 4$ as serving precisely this purpose.

Substitution is always is used on the end sequent. It is also affected by the syntactic restriction on sequents in Stoic logic. Thus the following rule is admissible: Substitution US1: When a Stoic sequent $\Sigma$ is provable, then any Stoic sequent $\Sigma^{\prime}$ obtained by uniformly substituting in $\Sigma^{\prime}$ propositions for atomic propositions in $\Sigma$ is also provable. (See $\S 1$ for 'Stoic 
sequent'.) It is easily seen that $\boldsymbol{U S \boldsymbol { I }}$ holds. The wording of the five axiomatic rules (and of the corresponding schemata A1-A5) makes the complexity of the propositions irrelevant. Moreover, it is impossible to uniformly substitute in such a way that instead of two distinct propositions the antecedent has two listings of the same proposition. This is so since $\boldsymbol{U S \boldsymbol { I }}$ requires that the result of any substitution in a provable Stoic sequent is itself a Stoic sequent. This prevents for example substitution of A for B in A7 or A8 (above $\S 4$ ). So the axiomatic rules (and A1-A5) do not restrict uniform substitution. The four themata (and the corresponding inference schemata T1-T4) are also phrased in such a way that the complexity of the propositions is irrelevant. By contrast, the following Substitution rule $\boldsymbol{U S} \boldsymbol{2}$ is not admissible: When a Stoic sequent $\Sigma$ is provable, then any sequent $\Sigma^{\prime}$ obtained by uniformly substituting in $\Sigma^{\prime}$ propositions for atomic propositions in $\Sigma$ is also provable. (Compare A6-A9 with $A 6^{\prime}-\mathrm{A} 9^{\prime}$ in $\left.§ 6.\right)$

Needless to say, from a Stoic perspective the lack of provability of sequents that are not Stoic sequents is no great loss. From a contemporary viewpoint, and with the assumption that Stoic antecedents are sets expressed in contemporary set notation, the admissibility in Stoic logic of $\boldsymbol{U S 1}$ instead of $\boldsymbol{U S} \boldsymbol{2}$ becomes negligible. This is so, since for any sequent $\Gamma$, A, A $\vdash$ B with cardinality of $\Gamma>0$ and that is provable in the Stoic system with $\boldsymbol{U S} \boldsymbol{2}$ there is a Stoic sequent $\Gamma, \mathrm{A} \vdash \mathrm{B}$ or $\Gamma, \mathrm{A}, \mathrm{B}^{*} \vdash \mathrm{A}^{*}$ that is provable without $\boldsymbol{U S} \boldsymbol{2}$. And from a contemporary perspective combined with sets as antecedents, $\Gamma, \mathrm{A}, \mathrm{A} \vdash \mathrm{B}$ and $\Gamma, \mathrm{A} \vdash \mathrm{B}$ are the same sequent and are equivalent to $\Gamma, \mathrm{A}, \mathrm{B}^{*} \vdash \mathrm{A}^{*} \cdot{ }^{43}$ This leaves the cases in which $\Gamma=\varnothing$ as the

\footnotetext{
${ }^{43}$ In Stoic logic, $\Gamma, A \vdash B$ and $\Gamma, A, B^{*} \vdash A^{*}$ are not equivalent. For example, the sequent $(p \oplus p) \oplus q$, $\neg \mathrm{q}, \mathrm{p} \vdash \neg \mathrm{p}$ has a Stoic proof (with one use of T3), but the sequent $(\mathrm{p} \oplus \mathrm{p}) \oplus \mathrm{q}, \mathrm{p} \vdash \mathrm{q}$ does not. Thus representation in the style of Tait calculi does not work for Stoic logic.
} 
only ones for which there can be no corresponding Stoic sequent, since there is only one antecedent formula. These are the cases recorded in $\S 6$ above.

To sum up so far: Permutation is straightforwardly admissible. Admissibility of Contraction is a trivial consequence of the Stoic syntactic constraints on sequents. Any uniform substitution rule (applied to the end sequent) has to be such that it honors the restrictions by those syntactic constraints. The rules with those syntactic constraints in place are absorbed by the Stoic axiomatic rules and inference rules. In this respect (the absorption of structural rules into logical rules), the Stoic system again resembles Kleene's analogues to Gentzen LK and LJ (Kleene 1952), which also partially absorb Gentzen's structural rules into its axiomatic rule or axiom schema, and are thus advantageous "in an upside down [scil. backward] search procedure for proofs of a given sequent" (Troelstra and Schwichtenberg 1996, 77).

This leaves the structural rule of Thinning (alias Weakening, Dilution, Monotonicity: $\Gamma \vdash \mathrm{A}$ $\Rightarrow \Gamma, \mathrm{B} \vdash \mathrm{A})$. In Stoic backward proof construction, Thinning would sanction the backward step from $\Gamma$, B $\vdash$ A to $\Gamma \vdash \mathrm{A}$ whenever $\Gamma \vdash \mathrm{A}$ is formally valid. We know that in Stoic logic, Thinning is not admissible. We have an example of an argument that corresponds to a sequent that is a first indemonstrable except that it has as an additional assumption an atomic proposition that otherwise does not occur in the sequent. The Stoics expressly classify this argument as invalid (S.E.M.8.431). Here is the corresponding sequent:

\section{1 $\mathrm{p}, \mathrm{p} \rightarrow \mathrm{q}, \mathrm{r} \vdash \mathrm{q}$.}

On the other hand, we know that the Stoics regard sequents like 
as valid, and it is as good as certain that they also maintain that sequents such as

\section{$7.3 \quad \mathrm{p} \rightarrow \mathrm{p}, \neg \mathrm{p} \rightarrow \mathrm{p} \vdash \mathrm{p}$}

are valid: ${ }^{44}$ Sequences 7.2 and 7.3 differ only in the assumption $p \oplus \neg p$, which is present in 7.2, absent in 7.3. So why is 7.1 invalid, but 7.2 not?

There is a straightforward answer to this question, which also sheds further light on Stoic analysis. As we saw in $\S 2$, for the Stoics the analysis of a sequent into one or more axioms is a necessary and sufficient condition for its (formal) validity or syllogismhood. Now, sequent 7.1 is not provable in Stoic logic - nor is the sequent in which the ' $r$ ' in 7.1 is replaced by ' $q$ '. By contrast, sequents 7.2 and 7.3 can both be analysed into axioms. (Sequent 7.2 is obtained by substituting $\mathrm{p}$ for $\mathrm{q}$ and $\neg \mathrm{p}$ for $\mathrm{r}$ in 5.3 from $\S 5$, where a seven-step analysis is given.)

${ }^{44}$ For 7.2 see e.g. Origenes Contra Celsum II.20 and Cicero De Fato 8-9; cf. S.E.M.8.466. Sequent 7.3 can be analysed into two A1 axioms in five steps:

A1

(4)

$\mathrm{p}, \mathrm{p} \rightarrow \mathrm{p} \vdash \mathrm{p}$

A1, T1

(3) $\quad \neg \mathrm{p} \rightarrow \mathrm{p}, \neg \mathrm{p} \vdash \mathrm{p} \quad \mathrm{p}, \neg \mathrm{p} \vdash \neg(\mathrm{p} \rightarrow \mathrm{p})$

$\mathrm{T} 2$

$\mathrm{T} 1$

(1) $\quad \mathrm{p} \rightarrow \mathrm{p}, \neg \mathrm{p} \rightarrow \mathrm{p}, \vdash \mathrm{p}$

For the as good as certain Stoic validity of $7.3 \mathrm{cf}$. e.g. Origen Contra Celsum VII.15. There a Stoic argument that differs in form from 7.3 only by having both premises in contraposition is assumed to be regarded as valid by the Stoics. $(\neg q \rightarrow \neg p, q \rightarrow \neg p \vdash \neg p$, with contraposition of the antecedent formulae and substitution of $\mathrm{p}$ for $\mathrm{q}$ and $\neg \mathrm{p}$ for $\mathrm{p}$.) 
So, Stoic analysis is not a method that just happens to produce the desired results with regard to the validity of certain sequents. It is a method that reflects the reasons why a sequent is (considered) formally valid. The sequent either is itself not in need of proof by analysis, or it can be analysed - and that is analysed completely - into sequents not in need of proof by analysis. Valid non-axiomatic sequents are said to be composed, or literally, braided together, from axioms. ${ }^{45}$ (There are hidden assumptions, just as in a braid there are parts of strands that are not visible, if one is willing to stretch the metaphor. See Becker 1957 and Bobzien 1996, pp.155-8 for diagrammatic illustration of the hidden assumptions.) Any antecedent proposition in a sequent for which no analysis makes it part of the braided axioms is superfluous and that sequent is not provable. Sequents 7.2 and 7.3 are both provable in Stoic logic. The fact that one can deduce the succedent $\mathrm{p}$ with and without the third antecedent proposition of 7.2 is irrelevant to the provability of 7.3. Keeping the antecedent propositions to a minimum has at most aesthetic or pragmatic significance.

The Stoic rejection of Thinning is thus a by-product of Stoic analysis. There is no specific rule that makes a sequent invalid for the sole reason that the succedent can be concluded from a proper subset of the antecedent propositions. Rather, it is precluded by the rules of Stoic analysis that one takes a valid sequent, creates a new sequent by haphazardly adding an antecedent proposition to this sequent, and in so doing preserves validity. By contrast, if one adds an antecedent proposition to, or subtracts one from, a valid sequent and the resulting sequent, too, has a proof (i.e. can be analysed into axioms by the inference rules), then that sequent, too, is valid.

\footnotetext{
${ }^{45}$ See fn 25. The Greek for 'composed' is pleketai. Passages with pleketai or the cognate ploke describe the way non-simple syllogisms are composed from simple ones: S.E.M.8.223 peplegmenoi 230 peplegmenoi, peplektai 234 plokēn, Gal.Plac.Hipp.Plat.2.3.19 plokē; also S.E.M.8.229 sunestōtes, 235 sunestēke.
} 
We can now also offer a logical explanation why the expression 'external' occurs in all surviving formulations of the third Stoic thema (above §3). In classical propositional sequent calculi (e.g. Gentzen propositional LK), T2 and T4 could be derived from T3 by means of Thinning and Contraction. There would be no need for cut rules beyond T3 (more precisely beyond T3 with unlimited antecedent formulae in the first premise). And those who declare that Stoic logic is classical (e.g. Becker 1957, Egli 1983) are left with the unanswered question what logical purpose the expression 'external' has in T3. But Stoic logic is substructural, since it does not contain Thinning. For syntactic reasons, it also has no application for Contraction. Given the absence of Thinning, and as a matter of convenience, substructural systems often introduce more than one cut rule. For example, they may use an additive or context-free cut rule and a multiplicative or context-sharing cut rule (e.g. Humberstone 2011, 349-350), which, for single-succedent sequents in their simple form would be

$$
\begin{aligned}
& A_{1}, A_{2} \vdash A_{3} ; \quad A_{3}, \Gamma \vdash A_{4} \Rightarrow A_{1}, A_{2}, \Gamma \vdash A_{4} \\
& A_{1}, A_{2} \vdash A_{3} ; \quad A_{1}, A_{2}, A_{3}, \vdash A_{4} \Rightarrow A_{1}, A_{2} \vdash A_{4}
\end{aligned}
$$

The additive $\mathrm{C} \oplus$ and the multiplicative $\mathrm{C} \otimes$ share features with $\mathrm{T} 2$ and $\mathrm{T} 3$, respectively. The $\Gamma$ in the additive rule would correspond to a multiset of external premises. It seems then that the term 'external premise' is the Stoic way of expressing the additive nature of a cut rule. If this is so, it provides additional validation for the reconstruction of the second and fourth themata as cut rules. ${ }^{46}$

\footnotetext{
${ }^{46}$ Could the Stoics have used as a single cut rule that combines the multiplicative and additive inheritance of assumptions the following: $\Gamma, \Delta \vdash \mathrm{A} ; \mathrm{A}, \Gamma, \mathrm{E} \vdash \mathrm{B} \Rightarrow \Gamma, \Delta, \mathrm{E} \vdash \mathrm{B}$ ? Not quite. It is true,
} 
Stoic analysis is, then, a relevance logic of proof search that is based on the idea that any valid (non-simple) non-axiomatic sequents can be dissected into axiomatic sequents, with the rationale that non-axiomatic sequents are nothing but a composition and reshuffling of axiomatic sequents, where the latter can be recovered by means of the method of analysis.

It is remarkable that the logic defined by Stoic analysis successfully avoids many of the sequents that relevance logicians have considered paradoxical and have tried to eliminate. We know that this is no coincidence. The Stoics almost certainly discussed analogues to the paradoxes of material and strict implication and appear to have aimed at eliminating them (S.E.M.109-117, S.E.PH.110-112, Cicero Acad.47, cf. Kneale \& Kneale 1962 pp.128-38). Fittingly, the Stoic system also evades the principle ex contradictione quodlibet. There are two straightforward single-succedent sequent-logical formulations, $\mathrm{A}, \neg \mathrm{A} \vdash \mathrm{B}$ and $\mathrm{A} \wedge \neg \mathrm{A} \vdash$ B. Only the first is a Stoic sequent, and it is evidently invalid. As has been shown elsewhere (Bobzien 1996, pp. 181-88), Stoic relevance logic shares further elements with a number of different theories of substructural logic, coming closest to that of Storrs McCall, but is not identical with any of them. (This is so even if one puts equivalents to the Stoic syntactic restrictions on the sequents of those logics.)

Like McCall's system of connexive implication (McCall 1966), the Stoic one lacks (analogues to) both 'And'-elimination and 'Or'-introduction. Neither is accidental. We obtain a consistent understanding of this exclusion, if the principle of redundancy that underlies the rejection of Thinning is thought to apply equally within simple sequents: every antecedent

$\Gamma=\varnothing$ provides $\mathrm{T} 3$ instances, $\mathrm{E}=\varnothing$ provides $\mathrm{T} 2$ instances, $\Delta$ and $\mathrm{E}=\varnothing$ provide $\mathrm{T} 2$ ' instances, and if neither $\Gamma$ nor $\mathrm{E}=\varnothing$ we have T4 instances. The combination of $\Gamma$ and $\mathrm{E}=\varnothing$ would however not square with Stoic sequent logic, since the second premise would not be a Stoic sequent. 
formula must be made use of to yield the succedent. The left 'And'-introduction rule ( $\mathrm{p} \wedge \mathrm{q} \vdash$ p) is not a Stoic sequent, and any addition of an antecedent formula either makes one antecedent formula redundant (e.g. adding $\mathrm{p}$ or $\mathrm{q}$ or $\mathrm{r}$ ) or does not yield a sequent (adding $\mathrm{p} \wedge \mathrm{q})$. The right 'Or'-introduction rule $(\mathrm{p} \vdash \mathrm{p} \oplus \mathrm{q})$ is no Stoic sequent either. The corresponding conditional $(\mathrm{p} \rightarrow(\mathrm{p} \oplus \mathrm{q}))$ is blatantly false, given the Stoic semantics of exclusive disjunction.

I conclude this section with two questions posed from the perspective of contemporary logic. The first is a question about T1: Can't the use of T1 lead from a provable Stoic sequent to a non-Stoic sequent, and therewith to a non-provable sequent? Take as example

$$
7.4 \quad \mathrm{p} \rightarrow(\mathrm{p} \rightarrow \neg \mathrm{p}), \mathrm{p} \vdash \neg \mathrm{p},
$$

which is provable, being a substitution instance of the provable (5.2) from $\S 5$. Does not a backward use of $\mathrm{T} 1$ on 7.4 produce a non-provable non-sequent as follows?

$$
\mathrm{p}, \mathrm{p} \vdash \neg(\mathrm{p} \rightarrow(\mathrm{p} \rightarrow \neg \mathrm{p}))
$$

(1) $\quad \mathrm{p} \rightarrow(\mathrm{p} \rightarrow \neg \mathrm{p}), \mathrm{p} \vdash \neg \mathrm{p}$

No. This case is precluded by the Stoic formulation of T1 (in §3), which requires that the succedent in the premise follow from two (or more) antecedent propositions - not from the same proposition taken twice. ${ }^{47}$ What about a backward use of T1 with 7.4 as premise? Does it not produce a proof of a non-provable non-sequent (based on the proof of (5.2)) as follows?

\footnotetext{
${ }^{47}$ When the case of two occurrences of the same proposition is permitted, the Stoics tend to say so explicitly in their definitions, cf. D.L.7.68-9.
} 
(1) $\quad \mathrm{p} \rightarrow(\mathrm{p} \rightarrow \neg \mathrm{p}), \mathrm{p} \vdash \neg \mathrm{p}$

(2) $\quad \mathrm{p}, \mathrm{p} \vdash \neg(\mathrm{p} \rightarrow(\mathrm{p} \rightarrow \neg \mathrm{p}))$

No. This case is barred by the requirement that the input expressions are Stoic sequents (i.e. arguments, e.g. D.L.7.78).

The second question is about T2-T4: Can't the use of the cut rules lead backwards from a provable conclusion to a case in which the second premise has the same proposition both as cut formula and in the multiset $\Gamma^{\prime \prime}$, as in the following case (with $\Gamma^{\prime \prime}(\mathrm{C})$ for $\Delta \cup \mathrm{C}$ )?

(2) $\quad \Gamma^{\prime} \vdash \mathrm{C} \quad \mathrm{C}, \Gamma^{\prime \prime}(\mathrm{C}) \vdash \mathrm{B}$ T2?, T3?, T4?

(1) $\quad \Gamma^{\prime}, \Gamma^{\prime \prime}(\mathrm{C}) \vdash \mathrm{B}$

Again, the Stoic formulation of the themata prevents such cases. Take T3 (i.e. $\Gamma^{\prime} \cap \Gamma^{\prime \prime}=\varnothing$ ) since the third thema is extant: 'When from two propositions a third follows, and from the third and one (or more) external proposition(s) another follows ...'. If the cut formula ('the third') occurred also as one of the external proposition(s), we would not have a Stoic sequent, and hence nothing would follow, that is we have no application of T3. What then, if we have the following two premises? 
Will a use of a cut theorem (e.g. T3 with $\Gamma^{\prime} \cap \Gamma^{\prime \prime}=\varnothing$ ) not lead to the case just presented and prevent us from proving $\Gamma^{\prime}, \Gamma^{\prime \prime}, \mathrm{C} \vdash \mathrm{B}$ ? Yes, but to no ill effect. We will simply have an application of a cut rule (e.g. T3) as follows:

(2) $\quad \Gamma^{\prime} \vdash \mathrm{C} \quad \mathrm{C}, \Gamma^{\prime \prime} \backslash\{\mathrm{C}\} \vdash \mathrm{B}$

(1) $\quad \Gamma^{\prime}, \Gamma^{\prime \prime} \backslash\{\mathrm{C}\} \vdash \mathrm{B}$

Likewise for T2 and T4.

\section{Normal Form, Subformula Property, Decidability and Efficiency}

The Stoics are on record for stating that all (valid) arguments are composed of, and can be reduced to, their indemonstrables (D.L.7.79, S.E.P.H.2.156). This has been taken as a completeness claim of sorts and has generated various attempts at filling in the details, including completeness proofs. ${ }^{48}$ My view is that it is unlikely that the Stoics had a notion of completeness comparable to that of contemporary logic, in particular since their logic was non-classical. The passages cited in support of completeness can be read as merely indicating that from the indemonstrables all other (valid) arguments get their validity.

\footnotetext{
${ }^{48}$ E.g. Frede 1974, pp. 196-98, Mueller 1979, Milne 1995, Bobzien 1996, pp. 188-92, Milne 2012.
} 
The fact that Stoic logic is a backward proof-search method suggests that the prevailing logical notion may have been that of decidability. The question would have been whether there is a method that determines in a finite number of steps of any Stoic sequent whether it has a derivation. Is there such a method $?^{49}$

Given its similarity to Gentzen's 1933 and 1934 systems, a natural starting point is to ask whether there is a normal form theorem for Stoic logic. We can exclude cut elimination as proved in Gentzen 1934, since the Stoic connectives are introduced by axioms, not inference rules. Gentzen 1933 appears more promising. ${ }^{50}$ Here, in one reading, the normal form requires that every cut has only axioms in its first premises. However, the Stoic system yields counterexamples that require a use of $\mathrm{T} 1$ in the first premise, such as cases in which a sequent $\mathrm{A}, \mathrm{B} \vdash \mathrm{A} \wedge \mathrm{B}$ is reducible to two axioms. Since Gentzen 1933 does not contain T1, we can weaken the above normal form requirement, so that it demands that every cut has only axioms and uses of $T 1$ in its first premise. This can be regarded as a Gentzen 1933 normal form requirement, since it is equivalent to saying that in every cut the first premise is cut free. This weakened requirement goes a certain way. Still, it falters in cases of provable sequents with what I call locked formulae. An example is (8.1), which does have a proof, but none with a cut-free first premise. In it the subformula $s \rightarrow r$ is 'locked'. It can only be reached with a cut in the first premise: $:^{51}$

\footnotetext{
${ }^{49}$ The next four paragraphs draw on results from Bobzien \& Dyckhoff forthcoming. I note here that the present paper was the first of the two to be written, and that due to circumstances beyond the authors' control the order of publication was reversed.

${ }^{50}$ It is immaterial here that Gentzen 1933 has Thinning. I am most grateful to Roy Dyckhoff, who first brought the relevance of Gentzen 1933 to my attention.

${ }^{51}$ The proof is given in Bobzien \& Dyckhoff forthcoming as Example 1.4. (Hint: it starts with T3 and sends the formulae with q into the first premise, those without q into the second, with cut formula $\neg$ p. It then uses T1, T2, T1 on the first premise, T3, T4, T3 on the second.) For a proof that no proof (derivation) of (8.1) has a cut-free first premise, and thus for a proof that there is no Stoic normal form theorem, cf. Bobzien \& Dyckhoff forthcoming, §10.
} 


$$
\mathrm{p} \rightarrow \mathrm{q}, \neg \mathrm{p} \rightarrow \mathrm{s}, \neg \mathrm{p} \rightarrow(\mathrm{s} \rightarrow \mathrm{r}), \neg(\mathrm{p} \wedge \mathrm{q}) \vdash \mathrm{r}
$$

Thus for Stoic logic there is no normal form theorem analogous to Gentzen 1934 or 1933.

The Stoic system does, though, include another pivotal property of Gentzen systems relevant to decidability. This is the subformula property (or analyticity property). A Stoic system contains the subformula property (has analyticity) iff in any proof of a Stoic sequent $\Gamma \vdash A$ only \pm subformulae of $\Gamma$ and A occur. An informal proof that the Stoic system has this subformula property is given in the Appendix. ${ }^{52}$

The Stoic subformula property entails that provability in the Stoic system is decidable. The number of \pm subformulae of the end sequent in a proof is finite, since all formulae are of finite length and depth and the number of antecedent formulae is finite. The sequents in any proof are then constrained in formula length and depth and number of formulae by those \pm subformulae of the end sequent. On the assumption that the Stoics operated a basic loop checker, decidability follows. ${ }^{53}$ Any proof of the subformula property utilizes the fact that each binary connective has only either a left rule (for conditional and disjunction 'elimination') or a right rule (for conjunction 'introduction'). Hence the decidability of Stoic logic depends fundamentally on this fact. Gentzen 1933 has no such restriction on axioms. I submit that it is this Stoic restriction that makes it possible in Stoic logic to have decidability

\footnotetext{
${ }^{52}$ A different, more elaborate, proof is offered in Bobzien and Dyckhoff forthcoming, §§4-7.

${ }^{53}$ The loop checker basically creates a record of the steps in a proof search and checks before any new provisional step whether such a step already occurred at some earlier point. If the answer is yes, a different step has to be chosen, and if there is none, that proof search is unsuccessful.
} 
even though it has an infinite number of axioms and does not have Thinning. ${ }^{54}$ This restriction prevents 'tonk'-arguments. It also does away with the advantages of having duals for left and right operational rules.

Decidability is not (yet) efficiency. ${ }^{55}$ The relevance criterion together with the subformula property and some further criteria permit considerable reduction of the proof search space. ${ }^{56}$ These additional criteria include the fact that the Stoic system can be interpreted as a fragment of classical propositional logic. Under a classical interpretation of the connectives for conditionals and exclusive disjunctions, and of the consequence relation, A1-A5 come out classically valid; T1-T4 preserve classical truth, and consequently classical validity. So, a decision procedure for classical logic can be used to reduce the search space: no classically invalid sequent is derivable in Stoic logic. Call this the classical validity criterion. Work on an implementation of the Stoic system (using Prolog) is in progress, but efficiency has as yet not been shown. A fortiori, there is insufficient evidence for the reconstruction of a Stoic proof-search method that entails efficiency. It is possible to offer some general remarks on Stoic method and reduction of proof-search space. First we can consider the surviving examples for analysis and the forms of propositional arguments for which there is evidence

\footnotetext{
${ }^{54}$ Doesn't classical propositional logic have infinitely many axioms when formulated in a Gentzenstyle sequent calculus? Isn't it decidable? True. But Gentzen has a normal form theorem, his Hauptsatz, whereas for the Stoics there seems to be no normal form theorem of any kind (although I am still looking). A different path is required for a proof of decidability, and for this path the restriction mentioned in the main text appears to be required.

${ }^{55}$ The notion of efficiency, though pervasive in automated theorem proving, is not (yet) well-defined. Whereas decidability concerns what can be proved, efficiency concerns how we prove. For present purposes (i.e. syntactic rather than semantic proof) efficiency refers generally to proof complexity: In particular, proof of decidability is not yet proof that a proof (derivation) can be found automatically or following some algorithm. Cut-elimination or some normal form theorem would suffice for efficiency. Given the absence of these in Stoic logic, some alternatives have to be explored. This is a subject for future research.
}

${ }^{56}$ See Bobzien and Dyckhoff forthcoming, $\S \S 8-9$ for some of these properties and their proofs. 
that the Stoics considered them valid. All of these are compatible with the basic method of backward proof search described in Bobzien 1996, of which the following is a modification that takes into account the proof-theoretical terminology favoured in this paper. (It is not suggested that any such description existed in antiquity; only that the method of proof search so far as we can reconstruct it, is such that this may be an adequate partial description.)

Check whether the input end sequent $(\Sigma 1)$ is an axiom. If so, you have a proof. If not, among the antecedent formulae of the end sequent search for two that produce an axiom $(\Sigma 2=\mathrm{Ax} 1)$ if a new formula $(\mathrm{C} 1)$ is added as succedent. If the end sequent has a proof, this new formula (cut formula $\mathrm{C} 1$ ), together with any remaining antecedent formulae, and/or one or both of the antecedent formulae used in the first premise, entail the succedent of the end sequent (the end succedent) - either by yielding an axiom (in which case you have a proof) or by yielding a new (end)sequent $(\Sigma 3)$ that, by use of $\mathrm{T} 1-\mathrm{T} 4$, can be analysed into one or more axioms. In the latter case, consider whether any two antecedent formulae of the new sequent $(\Sigma 3)$ are antecedent formulae to another axiom $(\Sigma 4=\mathrm{Ax} 2)$, with a new succedent $(\mathrm{C} 2)$, (in which case, provisionally apply $\mathrm{T} 3$, with $\mathrm{C} 2$ as cut formula). If there are no such two antecedent formulae, or $\Sigma 3$ has only the cut formula (C1) as antecedent formula, find out whether the addition of one of the antecedent formulae of the first premise $(\Sigma 4=\mathrm{A} \times 2)$ yields such an axiom with a new succedent (C2), (in which case, provisionally apply T2 or T4, with $\mathrm{C} 2$ as cut formula). If the thus-obtained new second premise $(\Sigma 5)$ is axiomatic, and all antecedent formulae of the end sequent have been used at least once, and the succedent of the new second premise $(\Sigma 5)$ is that of the end sequent, then the end sequent has a proof. If not, repeat the procedure with the new second premise $(\Sigma 5)$. Continue in this way until the antecedent formulae of the latest second premise entail the end succedent by forming an axiom (Ax3) with it, at which point you have a proof. If at any point in the analysis no axiom can be 
constructed, use $\mathrm{T} 1$ if the negation of the succedent of a non-axiomatic sequent yields the antecedent formulae for an axiom. Where there is a choice of antecedent formulae for a first premise or of cut formula, some backtracking may be required to complete the proof.

This basic method is related to the Gentzen-1933-style normal-form requirement that first premises must be cut free, except that it uses T2-T4 instead of Gentzen's Cut, and has precisely the axiom schemata A1-A5. Although the basic method covers all provable Stoic sequents which are evidenced, it does not cover provable sequents with locked formulae and thus does not make it decidable which sequents have no proof (pace Bobzien 1996). We do not know whether the Stoics would have considered the basic method complete. Either way it is of interest to consider what other or additional methods the Stoics could have used.

We can assume that they used some search-space reducing criteria of the kind mentioned above. Even if they had no formal proof, it would be surprising if they were unaware of the subformula property (or strengthened subformula property) and the relevance property (they denied Thinning, §7) in their system. These criteria allow one to cut down on input end sequents by rejecting those with \pm subformulae that occur once only and to cut down on choices for cut formulae where the basic method gives out. In either case it also restricts the depth and length of formulae that can occur in any premises, relative to the end sequent.

Furthermore, it is quite likely that the Stoics had some informal version of at least part of the classical validity criterion and used this to reduce the search space. Chrysippus (the Stoic who devised the logical system here discussed) was familiar with the classical (or Philonian) reading of the conditional (e.g. Cicero Acad.Pr.47, S.E.M.8.112-117) and with a presentation of the classical truth-conditions of connectives analogous to truth tables, as well as with the 
fact that his conditional is stronger than the classical (or Philonian) one (Cicero Fat.11-14). Chrysippus also had a general notion of semantic validity (i.e. one not restricted to his formal system) that is defined by a principle that has been associated with the Deduction Detachment Theorem: A Stoic sequent is valid when the conditional that consists of the conjunction of the antecedent assumptions as antecedent and the succedent as consequent is sound/true (S.E.P.H.2.137, S.E.M.8.415-17). ${ }^{57}$ Thus, although there is no evidence of a Stoic semantics for their 'proof theory', the Stoics had all the information required for using the classical validity criterion in order to reject without further testing sequents with true antecedent and false succedent.

All this still leaves unanswered the question how the Stoics would deal with proofs containing locked formulae. To illustrate how they could have advanced beyond guesswork in their proof search, even without a proof-search engine, here are some conjectural thoughts. First, the following strategy or division method is often successful with locked formulae. (i) Search for an atom that occurs in all (or most) non-simple antecedent formulae (in 8.1, p). (ii) Use it or its complement as cut formula. (iii) Divide the remaining formulae with respect to which other atoms occur in them (in 8.1: q on the one hand, $\mathrm{s}$ and $\mathrm{r}$ on the other). (iv) Choose the polarity of the cut formula based on the formulae which go into the first premise (above: positive, if the q-formulae go left, negative, if the $s$ and the $r$ formulae go left; no more than

\footnotetext{
57 Three remarks on the relation between Stoic truth, validity and provability: First, the Stoic conditional cited in the main text ('when ... sound/true') is not a biconditional. For example, in the Stoic view $(\mathrm{p} \wedge \mathrm{p}) \rightarrow \mathrm{p}$ is true, but $\mathrm{p}, \mathrm{p} \vdash \mathrm{p}$ is not a valid sequent. Second, a Stoic sequent can satisfy the validity criterion without being derivable, that is, without having a proof. For example, $p \rightarrow q$, ' $q$ is false' $\vdash \neg \mathrm{p}$ is a valid sequent, but it is not provable. It is not syllogistic; it is subsyllogistic (D.L. VII.78, see also §1). Third, in Stoic logic, the Deduction Theorem that if $\Gamma, A \vdash B$ is provable, so is $\Gamma$ $\vdash \mathrm{A} \rightarrow \mathrm{B}$ is not valid. For example, $\mathrm{p} \rightarrow \mathrm{q}, \mathrm{p} \vdash \mathrm{q}$ is provable but $\mathrm{p} \rightarrow \mathrm{q} \vdash \mathrm{p} \rightarrow \mathrm{q}$ is not. The formula $(\mathrm{p} \rightarrow \mathrm{q}) \rightarrow(\mathrm{p} \rightarrow \mathrm{q})$ is a Stoic logical truth because it is an instance of ' $\mathrm{A} \rightarrow \mathrm{A}$ ' (above and Cicero Acad.Pr.47), but it is not derivable from any provable sequent and is not a part of Stoic sequent logic. The Stoic principle more formally expressed would be 'If $\left(\mathrm{A}_{1} \wedge \ldots \wedge \mathrm{A}_{\mathrm{n}}\right) \rightarrow \mathrm{B}$ with $n \geq 2$ is sound/true, then $A_{1}, \ldots, A_{n} \vdash B$ is valid.'
} 
two formulae can go left). (v) Continue each branch with the basic method, supplemented with the division method just outlined as needed. ${ }^{58}$ Since the first premise in Stoic cuts has precisely two formulae, and we have the subformula property, generally cuts in the first premise will be by $\mathrm{T} 2$ possibly combined with T1. A list could have been produced of theorems (theōrēmata, above, §6) with two non-simple antecedent formulae which contain precisely the same two atoms and have a literal as succedent (to serve as cut formula). Some - presumably Stoic - logicians were carefully schooled in the use specifically of the first and second themata (Gal.Plac.Hipp.Plat.2.3.18).

\section{Conclusion}

Stoic logic has emerged as a substructural propositional single-succedent sequent logic that is highly principled, elegant, and strikingly original. Stoic syntax is comparable to those of contemporary propositional logics. It is combined with five meta-logical axiomatic rules (or meta-logical axiom schemata) and four inference rules. The result is a non-monotonic propositional logic that can handle substitution; that has absorbed the structural rule of Permutation; that trivially admits of Contraction; and that avoids many of the -seeminglyparadoxical sequents shunned by various relevance logicians. One can think of the Stoic inference rules and axiomatic rules as jointly defining the syntactic validity of sequents, or, in historical terms, the syllogismhood of arguments. The resulting Stoic concept of provability has its origin in the notion that sequents that are not evidently valid are composed of sequents that are evidently valid, and that an analysis of the non-evident sequents into the evident ones can be provided in a finite number of steps by the use of the logical rules - which reveal that

\footnotetext{
${ }^{58}$ This method may fail with substitution instances of a provable sequent in which different atoms are replaced by the same atom (or its negation).
} 
the non-evident sequents ensue from combining and reshuffling the evident ones. The term 'analysis' used by the Stoics for their proof-search logic thus accurately captures the main feature of their system.

Compared with contemporary theories of deduction for propositional logics, Stoic analysis itself has most points of similarity to methods of backwards proof search by proof construction for Gentzen-style sequent logics, as they have been developed more recently in the context of logic programming and automated theorem proving. When understood as a proof-search method in this way, the Stoic system of propositional logic emerges as decidable and possibly effective. The differences to contemporary Gentzen-style systems are just as striking. A deliberate choice of relevance over classical logic; the placing of logical structure in the axioms (leaves) rather than inference rules; the dispensability of double negation; the focus on decidability (rather than completeness); the integration of the directionality of proof search into the notion of provability; the choice of metalinguistic rules over axiom and inference schemata for reasons of economy - these are all thought-provoking alternatives that may enrich contemporary discussion. There are also several items that invite further research. Did the Stoics have any functional analogue to a normal form theorem? Did they have further principles to reduce the search space or methods to facilitate proof-search for more complex sequents? How are we to think of a semantics for Stoic sequent logic? Can we develop a suitable model theory and does the Stoic definition of analysis point us in any promising direction?

In sum, it is time that the Stoics gain the attention they deserve for their sequent logic: as the first architects of propositional logic and as ground-breaking pioneers of structural proof theory. 
Acknowledgements. I thank Roy Dyckhoff, Wilfrid Hodges, Stephen Menn, Stephen Read, Adrian Rezus, Charles Stewart, Wim Vanrie, the participants in the conference Analysis and Synthesis in Amsterdam in December 2013 and my audience at the Arché History and Philosophy of Logic and Mathematics Seminar, St Andrew's in April 2017 as well as two anonymous referees.

\section{References (ancient)}

Ammonius. 1899. In Aristotelis Analyticorum Priorum librum I commentarium, edited by M. Wallies, Berlin: G. Reimer (CAG IV.6). [Ammon.An. Pr.]

Aphrodisias, Alexander of. 1883. In Aristotelis Analyticorum Priorum librum I commentarium, Commentaria in Aristotelem Graeca, edited by M. Wallies, Berlin: G. Reimer (CAG II.1). [Alex.An.Pr.]

Apuleius. 1991. Peri Hermeneias, in De Philosophia libri, edited by C. Moreschini, Stuttgart \& Leipzig: Teubner. (Apulei opera quae supersunt vol.3.)

Cicero. 1922. Academica posteriora, Academica priora (Academicorum reliquiae cum Lucullo), edited by O. Plasberg, Leipzig. Reprinted 1966. Stuttgart. [Acad.]

Cicero, M. Tullius. 1938. De divinatione—-De fato-Timaeus, edited by W. Ax, Leipzig: Teubner. Reprinted 1965. Stuttgart.

Empiricus, Sextus. 1914. Adversus Dogmaticos libri quinque, in I.H. Mutschmann and J. Mau, Opera, Volume II, and Stuttgart and Leipzig: B.G. Teubner. Reprinted Stuttgart and Leipzig: Teubner. 1958. [S.E.M.]

ـ 1958. Pyrrhoneion Hypotyposeon libri tres, in I.H. Mutschmann and J. Mau, Opera, Volume I, 2 ed, and Stuttgart and Leipzig: Teubner. [S.E.P.H.]

Galen. 1879, 1965. Historiae Philosophiae, in H. Diels, Doxographi Graeci, 615.5-6:371, and Berlin: de Gruyter. [Gal.Hist.Phil.] 1896. Institutio Logica, Leipzig: Teubner. [Gal.Inst.Log.] 1978-80. De Placitis Hippocratis et Platonis, edited by P.H. De Lacy, 3 volumes, Corpus Medicorum Graecorum V.4.1.2, Berlin: Akademie Verlag. [Gal.Plac.Hipp.Plat.] 
Laertius, Diogenes. 1999. Lives of the Philosophers, edited by M. Marcovich, 2 volumes, Stuttgart \& Leipzig: Teubner.

Origen. 2001. Contra Celsum, edited by M. Marcovich, Leiden: Brill.

Simplicius. 1894. In Aristotelis De Caelo commentaria, in J.L. Heiberg, Commentaria in Aristotelem, Volume VII, and Berlin: G. Reimer. [Simpl.Arist.Cael.]

\section{References (contemporary)}

Becker, O. 1957. Zwei Untersuchungen zur antiken Logik (= Klassisch-philologische Studien 17), Wiesbaden: Harrassowitz.

Bernays, P. 1945. 'Review: Oiva Ketonen, Untersuchungen zum Pradikatenkalkul', Journal of Symbolic Logic, 10 (4), 127-30.

Bobzien, S. 1996. 'Stoic Syllogistic', Oxford Studies in Ancient Philosophy, 14, 133-92. 1999. 'Stoic Logic', in K. Algra, J. Barnes, J. Mansfeld and M. Schofield, The Cambridge History of Hellenistic Philosophy, and Cambridge: Cambridge University Press.

— 2011. 'The Combinatorics of Stoic Conjunction', Oxford Studies in Ancient Philosophy, 40, 157-88.

Bobzien, S., and R. Dyckhoff. Forthcoming. 'Analyticity, Balance and Non-admissibility of Cut in Stoic Logic', Studia Logica.

Corcoran, J. 1974. 'Remarks on stoic deduction', In J. Corcoran, Ancient Logic and its Modern Interpretation, and Dordrecht (Holland): Reidel Publishing Company.

Dyckhoff, R., and S. Negri. 2012. 'Proof Analysis in Intermediate Logics', Archive for Mathematical Logic, 51, 71-92.

Egli, U. 1983. 'The Stoic Theory of Arguments', in R. Bäuerle, C. Schwarze and A. von Stechow, Meaning, Use, and Interpretation of language, and Berlin: Walter de Gruyter.

Fitting, M. 1996. First-Order Logic and Automated Theorem Proving, 2 ed, Graduate Texts in Computer Science, New York: Springer.

Frede, M. 1974. Die stoische Logik, [Abhandlungen der Akademie der Wissenschaften zu Göttingen, 3. Folge, 88, Philologisch-Historische Klasse] (Habilitationsschrift, Göttingen 1972), Göttingen: Vandenhoeck \& Ruprecht.

Frege, G. 1879. Begriffsschrift: eine der arithmetischen nachgebildete Formelsprache des reinen Denkens, Halle: Nebert. 
Gabbay, D.M., and J. Woods. 2004. Handbook of the History of Logic. Vol. 1, Greek, Indian and Arabic logic, Amsterdam: Elsevier.

Gentzen, G. 1933. 'Über die Existenz unabhängiger Axiomensysteme zu unendlichen Satzsystemen', Mathematische Annalen, 107, 329-50.

1934. 'Untersuchungen über das logische Schließen. I', Mathematische Zeitschrift, 39 (2), 176-210. English translation: Gentzen, G. 1964. 'Investigations into Logical Deduction II', American Philosophical Quarterly, 2 (3), 204-18, Transl. Szabo, M.E. Also in Szabo, M.E. 1969. The Collected Works of Gerhard Gentzen, North-Holland Publishing Company. . 1935. 'Untersuchungen über das logische Schließen. II', Mathematische Zeitschrift 39, (3), 405-31. English translation: Gentzen, G. 1964. 'Investigations into Logical Deduction I', American Philosophical Quarterly, 1 (4), 288-306, Transl. Szabo, M.E. Also in Szabo, M.E. 1969. The Collected Works of Gerhard Gentzen, North-Holland Publishing Company.

S., Graham-Lengrand. 2013. 'Psyche: A Proof-Search Engine Based on Sequent Calculus with an LCF-Style Architecture', in D. Galmiche and D. Larchey-Wendling, Automated Reasoning with Analytic Tableaux and Related Methods, TABLEAUX 2013, Lecture Notes in Computer Science, Volume 8123, and Berlin, Heidelberg: Springer.

Gould, J. 1974. 'Deduction in Stoic Logic', In J. Corcoran, Ancient Logic and its Modern Interpretation, and Dordrecht (Holland): Reidel Publishing Company.

Hilbert, D. 1922. 'Neubegründung der Mathematik. Erste Mitteilung', Abhandlungen aus dem Seminar der Hamburgischen Universität, 1, 157-77. English Translation in Ewald, W. 1996. From Kant to Hilbert. A Source Book in the Foundations of Mathematics, 2 volumes, Oxford: Clarendon Press.

1923. 'Die logischen Grundlagen der Mathematik', Mathematische Annalen, 88, 151-65.

English Translation in Ewald, W. 1996. From Kant to Hilbert. A Source Book in the Foundations of Mathematics, 2 volumes, Oxford: Clarendon Press.

Hitchcock, D. 2006. 'The peculiarities of Stoic logic', in A. D. Irvine and K. A. Peacock, Mistakes of Reason: Essays in Honour of John Woods, and Toronto: University of Toronto Press.

Humberstone, Lloyd. 2011. The Connectives, Cambridge, MA: MIT Press.

Ierodiakonou, K. 1990. Analysis in Stoic Logic, London: PhD Thesis.

Jaskowski, S. 1934. 'On the rules of suppositions in formal logic', in J. Łukasiewicz, Studia Logica. Wydawnictwo Poswiecone Logice i jej Historii [Studia Logica. Publications on Logic and its History]. Reprinted in Mc-Call, S. 1967. Polish Logic 1920-1939, Oxford: Clarendon Press. Jennings, R.E. 1994. The Genealogy of Disjunction, Oxford: Oxford University Press. 
Ketonen, O. 1944. Untersuchungen zum Prädikatenkalkül. Helsinki: Annales Academiae Scientiarum Fennicae, series A, vol.I. Mathematica-physica 23.

Kleene, S.C. 1952. Introduction to Metamathematics, Amsterdam: North-Holland Publishing Co, and Groningen: P. Noordhoff.

Kneale, W., and M. Kneale. 1962. The Development of Logic, Oxford: Oxford University Press.

Lincoln, P. 1995. 'Deciding provability of linear logic formulas', in J. Girard, Y. Lafont and L. Regnier, Proceedings of the workshop on Advances in linear logic, and New York: Cambridge University Press New York.

Łukasiewicz, J. 1935. 'Zur Geschichte der Aussagenlogik', Erkenntnis, 5, 111-31. (Translated by the author from the Polish 'On the history of the logic of propositions' 1934). Translated in McCall, S. 1967. Polish Logic 1920-1939, Oxford: Clarendon Press.

Mates, B. 1962. Stoic Logic, 2 ed, Berkeley and Los Angeles: University of California Press. (First edition 1953).

McCall, S. 1966. 'Connexive Implication', Journal of Symbolic Logic, 31, 451-33.

Mignucci, M. 1993. 'The Stoic Themata', in K. Doering and Th. Ebert, Dialektiker und Stoiker, and Stuttgart: Franz Steiner.

Milne, P. 1995. 'On the completeness of non-Philonian Stoic logic', History and Philosophy of Logic, $16,39-64$.

- 2012. Completeness theorems of Stoic logic, Unpublished manuscript.

Mueller, I. 1979. 'The completeness of Stoic logic', Notre Dame Journal of Formal Logic, 20, 201-15.

Muñoz Toriz, J.P., I. Ruiz Martinez, and J.R.E. Ramirez-Arrazola. 2014. 'On Automatic Theorem Proving with ML', in Proceedings of the 13th Mexican International Conference on Artificial Intelligence (Special Sessions).

Negri, S., and J. von Plato. 2001. Structural Proof Theory, Cambridge: Cambridge University Press.

Restall, G. 2000. An Introduction to Substructural Logics, London: Routledge.

S., Graham-Lengrand. 2013. 'Psyche: A Proof-Search Engine Based on Sequent Calculus with an LCF-Style Architecture', in D. Galmiche and D. Larchey-Wendling, Automated Reasoning with Analytic Tableaux and Related Methods, and Berlin, Heidelberg: Springer.

Smullyan, R.M. 1968. First-Order Logic, Berlin, New York: Springer. Reprinted with new preface 1995. Dover Publications: New York.

Troelstra, A.S., and H. Schwichtenberg. 1996. Basic Proof Theory, Cambridge tracts in theoretical computer science, Cambridge, New York, and Oakleigh, Victoria: Cambridge University Press. 


\section{Appendix: Informal proof sketch of the subformula property for Stoic sequent logic}

This sketch is for a more straightforward proof than the one in Bobzien and Dyckhoff forthcoming. The goal is to keep close to terminology and distinctions known from the Stoics. A Stoic proof system has the \pm subformula property precisely if in any proof (derivation) of a Stoic sequent $\Gamma \vdash A$ only \pm subformulae of $\Gamma$ and A occur (above $\S 8) .{ }^{59}$

\section{Syntactic distinctions: Schemata, formulae and basic forms}

Sequents as they appear in the proof rules, including axiom schemata, are called sequent schema. Structurally, the formulae are divided into the atoms and the connectives (i.e. $\oplus, \rightarrow$, and $\wedge, \neg$ ). Negation is allowed to be characterized either as an outermost unary connective $(\neg)$ or as instantiation of the contradictoriness operator $*$ in a sequent schema as defined in $\$ 2$ of the main paper. Note that each formula has precisely one of the following eight basic forms: positive and negative literals; formulae governed by $\oplus, \rightarrow$, or $\wedge$; negations of formulae governed by $\oplus, \rightarrow$, or $\wedge$.

\section{Definitions: Weight}

First, some definitions on formulae taken in isolation or in relation to a sequent: Some intuitive terms that are used in the proof, namely arity, content and size, are defined for all formulae. Weight is defined with respect to formulae in sequents. It is the crucial invariant that makes the proof work. Definitions of major and minor formulae in axioms make it possible to relate axioms to cut formulae.

DEFINITION 1. The content of $\mathrm{A}$ is $\mathrm{A}$, if $\mathrm{A}$ is an atom or formula governed by a binary connective. The content of $\neg \mathrm{A}$ is $\mathrm{A}$.

DEFINITION 2. The arity of an atom or a formula governed by a binary connective is +1 . The arity of $\neg \mathrm{A}$ is -1 .

DEFINITION 3. The weight of a formula occurring in a sequent depends on the product of two numbers. (i) Arity of the formula. (ii) Position in relation to the turnstile: +1 if the formula occurs to the right of the turnstile, -1 if it occurs to its left. Then, if the product is +1 , the weight is "right", otherwise it is "left".

Note that in applications of the cut themata (i.e., T2, T3 and T4), the arity and content of the cut formulae in the two premises are the same, but the weights are opposite.

\footnotetext{
${ }^{59}$ Thanks go to Charles Stewart for suggestions for the representation of parts of this proof.
} 
DEFINITION 4. The size of a formula is the number of binary connectives it is formed from.

Note that for any axiom, one of the three antecedent and succedent formulae is larger than the other two, which are \pm subformulae of it.

DEFINITION 5. The major formula of an axiom is the largest antecedent formula; the other two are minor formulae.

Note that the weight of the major formula in A1 and A2 axioms, which introduce $\rightarrow$, and in A4 and A5 axioms, which introduce $\oplus$, is left; in A3 axioms, which introduce $\wedge$, the weight is right.

\section{Ancestors and descendants}

Next, some relationships between similar formulae in a proof: These need to be specified, together with their properties, for each rule.

DEFINITION 6. The sequent occurrences of a proof are the sequents in a proof that are placed above or below rule applications. The formula occurrences, or just occurrences, are the formulae in a sequent occurrence.

Thus we can talk of the places where sequents and formulae occur in a proof.

DEFINITION 7. There is a partial function that maps occurrences in the premise sequent(s) of each thema application in a proof to occurrences in the conclusion, which we call the descendants. (i) The premise occurrences in $\Gamma$ (in applications of T1) and in $\mathbf{E}$ (in applications of T2-T4) have as descendants their occurrences in the conclusion. (ii) In applications of T1, the descendants of A and B are the instantiations in the sequent schema of $\mathrm{A}^{*}$ and $\mathrm{B}^{*}$, respectively. (iii) In applications of T2-T4, the cut formula in either antecedent sequent has no descendants. (iv) In applications of T2-T4, the descendants of $\mathrm{A}, \mathrm{B}$, and $\mathrm{D}$ are their occurrences in the conclusion.

Note that the descendant of any formula has the same weight and content as the formula.

Note that every formula in the conclusion of the application of a thema occurs in at least one premise sequent as a \pm subformula which is a non-cut formula, so that there is an inverse map from sets of concluding occurrences to non-empty sets of occurrences. Elementary reflection that could be formalised using the algebra of relations shows that chaining together instances of the descendant 
partial function downwards will end either at a cut formula or at the conclusion; tracing back from any conclusion along the inverse maps upwards will reach one or several leaves.

DEFINITION 8. The occurrences reachable from an occurrence by iteratively applying the descendant partial map are the descendants of that occurrence, and the final descendant is the lowest descendant. The inverse of the descendant partial function gives the ancestor relation. The ancestors of an occurrence are the occurrences reachable by successively composing the ancestor relation. The initial ancestors of an occurrence are the ancestors that are leaves.

\section{Subformula relationships}

Now the main results can be proved.

PROPOSITION 9. Every final descendant has as its ancestors only \pm subformulae of itself.

This follows directly from DEFINITIONS 7 and 8.

PROPOSITION 10. Every cut formula is a strict \pm subformula of the major formula of some axiom.

Proof by cases: (i) If the cut formula is a literal, then the initial ancestor of its cut occurrences can only be minor formulae of the axioms. (ii) If the cut formula is governed by $\oplus$ or $\rightarrow$, then one of the cut occurrences is weighted right, so its initial ancestor cannot be a major formula. Likewise, if the cut formula is the negation of a formula governed by $\wedge$, then one of the cut occurrences is weighted left, and so its initial ancestor cannot be a major formula. (iii) If the cut formula is governed by $\wedge$, then when the cut occurrence is weighted left, its initial ancestor cannot be a major formula. Likewise, if the cut formula is governed by the negation of a formula governed by $\oplus$ or $\rightarrow$, then when the cut occurrence is weighted left, the initial ancestor cannot be a major formula.

THEOREM 11. Every cut formula is a strict \pm subformula of some major formula whose final descendant is in the conclusion.

Proof: For a contradiction, assume the converse. Order the cut formulae by size and choose one of maximum size. Then by PROPOSITION 10, this cut formula is a strict \pm subformula of some major formula of an axiom. The final descendant of that formula must either be in the conclusion, or a cut formula of greater size than the one chosen. Either way, we have a contradiction.

THEOREM 12. In any proof of a Stoic sequent $\Gamma \vdash A$ only \pm subformulae of $\Gamma$ and A occur.

This follows directly from PROPOSITION 9 and THEOREM 11. 